\title{
Two Paths to Oxidative C-H Amination Under Basic Conditions: A Theoretical Case Study Reveals Hidden Opportunities Provided by Electron Upconversion
}

\author{
Paul Eckhardt, ${ }^{\ddagger, a}$ Quintin Elliott, ${ }^{\ddagger, b}$ Igor V. Alabugin ${ }^{\star, b}$ and Till Opatz ${ }^{*, a}$
}

\begin{abstract}
Traditionally, cross-dehydrogenative coupling (CDC) leads to $\mathrm{C}-\mathrm{N}$ bond formation under basic and oxidative conditions and is proposed to proceed via a two-electron bond formation mediated by carbenium ions. However, the formation of such high-energy intermediates is only possible in the presence of strong oxidants, which may lead to undesired side reactions and poor functional group tolerance. Alternatively, oxidation under basic conditions allows the formation of three-electron bonds. In a three-electron bond, two electrons will occupy a bonding orbital and the third is forced into a high energy anti-bonding orbital (resulting in an "upconverted" highly-reducing species). The benefit of this "electron upconversion" process is in the ability to use milder oxidants (e.g., $\mathrm{O}_{2}$ ) and to avoid highenergy carbenium ion intermediates. To explore the scope of this approach, we directly compared twoand three-electron pathways using quantum mechanical calculations. We observed that the absence of a strong oxidant can shut down two-electron pathways in favor of a three-electron path. Additionally, we investigated key factors involved in the three-electron $\mathrm{C}-\mathrm{N}$ bond formation by analyzing the cyclization of 42 radical anions. An interesting stereoelectronic feature for the reaction of highly stabilized diester anions is that only one of the ester groups is involved in the extra electron delocalization in the cyclized radical anion product. Hence, the effect of unproductive reactant stabilization can be removed in the cyclizations of monoester enolates rendering such reactions much more thermodynamically favorable.
\end{abstract}

\section{Introduction}

Initially, cross-dehydrogenative coupling (CDC) described transition metal catalyzed reactions developed to form $\mathrm{C}-\mathrm{C}$ bonds through oxidative coupling of two $\mathrm{C}-\mathrm{H}$ units..$^{1-4}$ Over the years CDC has evolved into a universal tool for the construction of $\mathrm{Y}-\mathrm{Z}$ bonds starting from $\mathrm{Y}-\mathrm{H}$ and $\mathrm{Z}-\mathrm{H}$ units (Figure 1a). The reaction may proceed either intermolecularly or intramolecularly in the coupling of $Y$ and $Z$, which include a carbon and a heteroatom (e.g., $\mathrm{N}, \mathrm{O}, \mathrm{Si}, \mathrm{P}, \mathrm{S}, \mathrm{Sn})$. $^{5-10}$

As the scope of CDC reactions widened, they have been performed under a broader variety of conditions through a number of mechanistic pathways, even under metal-free conditions. ${ }^{5,11}$ In the absence of metals, a variety of scenarios for the formal loss of $\mathrm{H}_{2}$ are possible (Figure $1 \mathrm{~b}$ ). All of them involve a combination of several of the following elementary steps: deprotonation, oxidation, $\mathrm{H}$-atom abstraction, and hydride abstraction.

This is accomplished by activation of $\mathrm{Y}-\mathrm{H}$ in the presence of the nucleophilic Z-H moiety. Most often, this bond is suggested to form via a reaction between a cation and a nucleophile. Methods for cation formation include formal hydride loss accomplished by removal of either a hydrogen atom and an electron, ${ }^{12}$ or a proton and two electrons. ${ }^{13-17}$ Occasionally, the $Y-Z$ bond can be formed via recombination of two a)

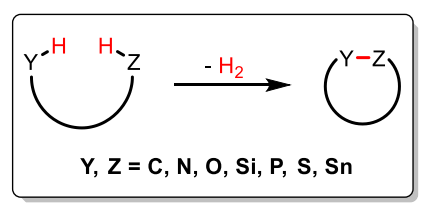

b)

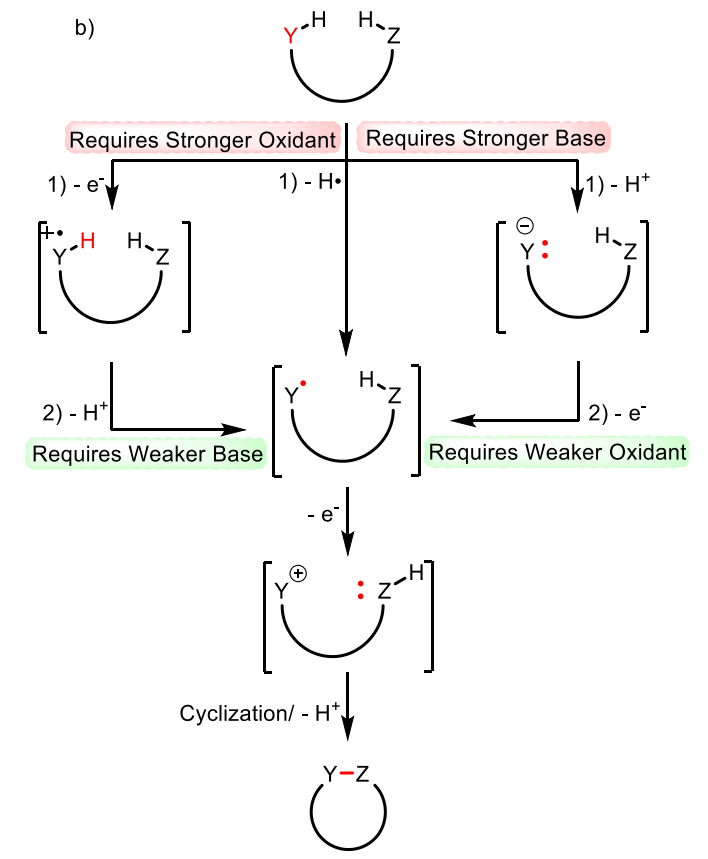

Figure 1. Schematic representation of possible pathways for $C D C$ reactions with the overall formal loss of $\mathrm{H}_{2}$ via a two-electron bond formation. More combinations are possible (vide infra).

radical centers, $Y$ and $Z .{ }^{18-20}$ Although multiple pathways exist to reach the final products, the commonly suggested scenarios for $\mathrm{Y}-\mathrm{Z}$ bond formation mostly involve formation of a classic

\footnotetext{
a Department of Chemistry, Johannes Gutenberg University, Duesbergweg 10-14, 55128 Mainz, Germany. E-mail: opatz@uni-mainz.de

${ }^{b}$ Department of Chemistry and Biochemistry, Florida State University, Tallahassee, Florida 32306, USA. E-mail: alabugin@chem.fsu.edu
} 
two-electron bond as the last step to conclude the CDC cascade. However, these pathways do not paint the whole picture and there are additional approaches to consider.

A conceptually different mechanistic approach involves utilizing an odd number of electrons for the $Y-Z$ bond formation (Figure 2). ${ }^{21,22}$ For example, a two-center one-electron bond $(2 c, 1 e)$ may be formed upon removal of a hydrogen atom and a hydride resulting in the coupling of radical and cation. ${ }^{23}$ Alternatively, removal of a hydrogen atom and a proton allows for the coupling of a radical and anion to form a two-center three-electron (2c,3e) "half-bond". This last approach is intriguing as it involves "electron upconversion" (eU), ${ }^{24}$ a conceptually interesting phenomenon of direct importance for the design of "electron-catalyzed" reactions. ${ }^{25}$

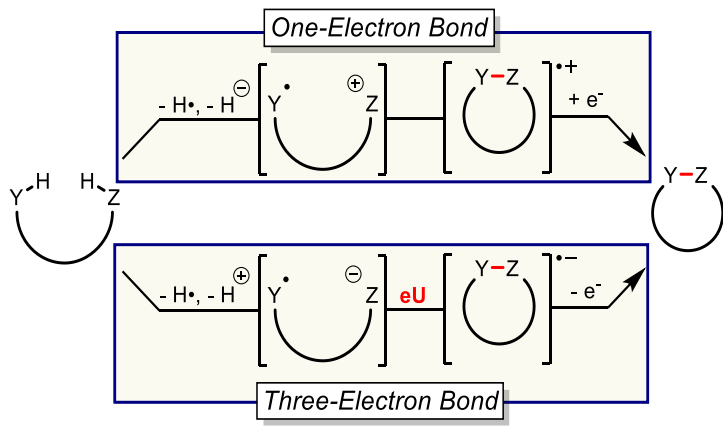

Figure 2. Schematic representation of odd-electron bond formations. Top: One-electron bond formed between a radical and a cation. Bottom: Threeelectron bond formed between a radical and anion.

In contrast to a typical exergonic redox reaction, where the reactants are stronger reductants than the products, electron upconversion transforms a relatively weak reductant into a more potent reductant in a thermodynamically favorable manner. ${ }^{26-29}$ This transformation is made possible by moving ("upconverting") one electron from a non-bonding orbital into a higher energy anti-bonding orbital via a $2 \mathrm{c}, 3 \mathrm{e}$ bond (Figure $3 .^{30}$ As a consequence, electron upconversion allows one to forge the final $Y-Z$ bond via a facile one-electron transfer to a very mild oxidant.

The selective amplification of reductive potential by creating the high-energy upconverted singly occupied MO (SOMO) could be used for the construction of reaction sequences which may not tolerate stronger oxidants.

For example, Alabugin and coworkers have demonstrated two variants of electron upconversion in $\mathrm{C}-\mathrm{H}$ amination of unprotected anilines and amides. In these examples the
$(2 c, 3 e)$ half-bond is formed by a nitrogen-anion and a carbon radical center. ${ }^{30,31}$ Because the intermediate containing the $(2 c, 3 e)$ half-bond has a much higher reduction potential than other species present in the reaction, it can be selectively oxidized by a relatively mild oxidant, e.g., molecular oxygen. Additional examples of redox chains mediated by highly reducing upconverted radical anion intermediates continue to appear, e.g., a photochemical thiolyne click reaction reported by Ananikov et al., ${ }^{32}$ hydroxylation reaction of aryl halides with oximes by James et al. ${ }^{33}$ and a number of other transformations. ${ }^{34-41}$

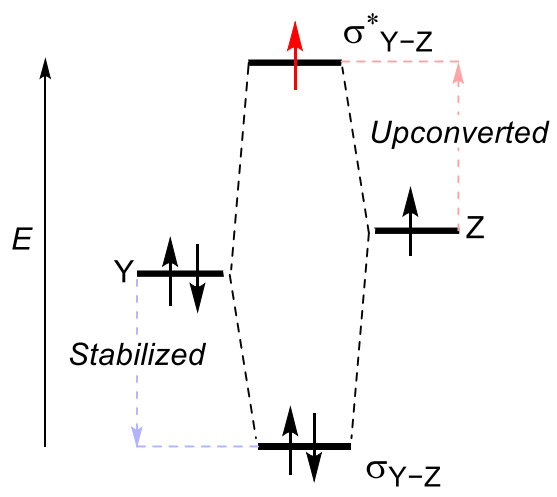

Figure 3. Schematic representation of electron upconversion. The upconverted electron is highlighted in red. ${ }^{30,31}$

Herein, we will use quantum-mechanical calculations to investigate whether a threeelectron bond formation with electron upconversion can be a viable alternative for these transformations. In particular, we will evaluate literature $\mathrm{C}-\mathrm{N}$ bond forming reactions proposed to proceed via a two-electron pathway (e.g, a nitrogen nucleophile attacking a carbenium ion). This analysis is guided by a hypothesis that the preferred reaction path can be switched from a two-electron pathway to a three-electron pathway when a mild oxidant is used instead of a stronger one.

\section{Computational methods}

Density-functional theory (DFT) calculations were carried out using the GAUSSIAN 16 Rev A.03 program package. ${ }^{42}$ Geometry optimizations and frequency calculations were carried out at the (U)M06-2X/6-31+G(d,p) level of theory ${ }^{43-46}$ including Grimme's D3 correction for empirical dispersion ${ }^{47}$ and the implicit SMD solvation model ${ }^{48}$ to simulate the effects of acetonitrile (MeCN), dibutyl ether (DBE), N,Ndimethylformamide (DMF), dimethyl sulfoxide (DMSO) or water. DBE ( $\varepsilon$ around 3.0$)^{49}$ was 
chosen as the solvent because of the similar dielectric constant to methyl tert-butyl ether $(\varepsilon$ ca. 2.6$)^{50}$, which was used as the main solvent in the work of $\mathrm{Xu}$ et al. (vide infra) but is presently not implemented in the GAUSSIAN program package. ${ }^{51}$ DMF $(\varepsilon 37.2)$ was chosen based on the work of Alabugin et al. Water ( $\varepsilon$ 78.4) was used to compare the results with a solvent of even higher polarity. Tight cutoffs on forces and step size were used (opt = tight). Frequency calculations were used to identify the structures as minima or transition states (TS). Unless otherwise stated, the presented results were produced at the (U)M06-2X(D3)/6$31+G(d, p) /(o p t=t i g h t) /(S M D)$ level of theory. CAS $(3,3)$ and DLPNO-CCSD $(T)^{52}$ single point calculations were carried out using the ORCA 4.2.1 program package ${ }^{53-55}$, utilizing the 6$31+\mathrm{G}(\mathrm{d}, \mathrm{p})$ basis $\operatorname{set}^{46}(\mathrm{CAS}(3,3))$ and the ccpVTZ basis set ${ }^{56,57}$ (DLPNO-CCSD $(T)$ ) with the TightSCF and TightPNO keywords and the optimized geometries obtained from DFT calculations. Three-dimensional depictions and spin density plots were produced with Chemcraft 1.8. ${ }^{58}$ Further details can be found in the Electronic Supporting Information (ESI).

\section{Results and discussion}

Our focus will be on representative $\mathrm{C}-\mathrm{N}$ bondforming cyclizations under basic conditions in the presence of an oxidant. Commonly, the proposed $\mathrm{C}-\mathrm{N}$ bond forming steps either involve formation of a high energy carbenium ion (a step that requires a strong oxidant) or alternatively, a vague "bond forming step". To address such mechanistic ambiguities, we sought to evaluate the relative thermodynamic profiles for the two main $\mathrm{C}-\mathrm{N}$ bond forming paths, i.e., the cation/nucleophile (two-electron) and the anion/radical (three-electron) pathways (Figure 4).

Oxidative $\mathrm{C}-\mathrm{N}$ bond formation has to involve a formal loss of $\mathrm{H}_{2}$. Under basic conditions, this process is usually accomplished via the loss of two protons and two electrons. ${ }^{51,59}$ However, the sequence of these four elementary steps can be accomplished in different orders. A typically proposed reaction mechanism involves the sequence of deprotonation/oxidation followed by oxidation/deprotonation. ${ }^{17}$ This is the sequence that leads to the formation of a carbenium ion which is then intercepted by a nitrogen nucleophile (left pathway of Figure 4). ${ }^{60-62}$ Although this process appears plausible, the formation of a cation generally requires a strong oxidant. ${ }^{63-66}$
An alternative radical pathway proceeds via the sequence of deprotonation/H-atom abstraction with cyclization/oxidation as the final step. In this process, the $\mathrm{C}-\mathrm{N}$ bond is formed at an intermediate stage via the reaction of an anion and a radical. An interesting feature of this step is that it upconverts an electron, i.e., transforms a weakly reducing anion into a strongly reducing radical anion (right pathway of Figure 4). ${ }^{24}$ By taking advantage of upconversion, one can perform the same reaction with milder oxidants. ${ }^{67}$ This feature can be valuable from a practical point of view. For example, the use of less aggressive oxidative conditions may allow for the preservation of sensitive functional groups that might otherwise be affected.

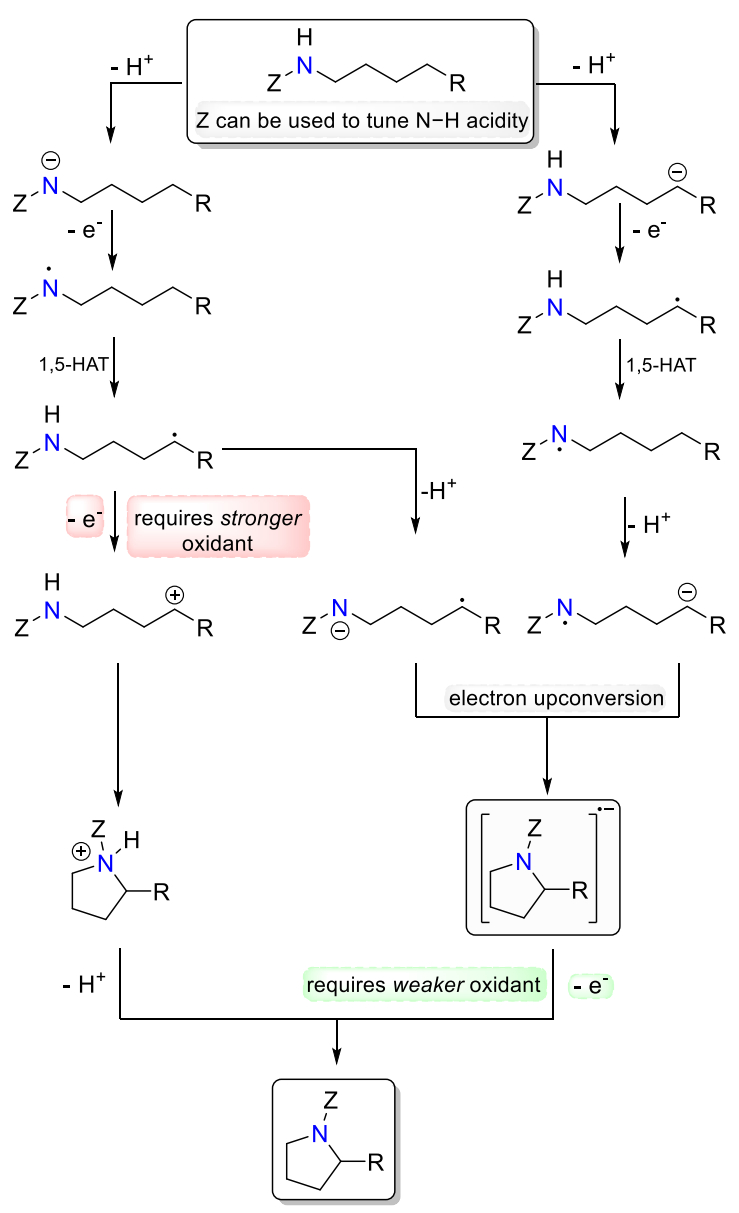

Figure 4. General mechanism for $\mathrm{C}-\mathrm{N}$ bond formation under basic and oxidative conditions. Left pathway shows a commonly proposed carbenium ion intermediate. Right pathway shows a conceptually different approach (eU mechanism) that requires milder oxidative conditions to reach the same product.

Figure 5 shows examples of $\mathrm{C}\left(\mathrm{sp}^{3}\right)-\mathrm{H} / \mathrm{N}-\mathrm{H}$ cross-coupling reactions under basic and oxidative conditions. Both examples have malonate moieties reacting as pronucleophiles. 
51, 68 No specific $\mathrm{C}-\mathrm{N}$ bond forming step was proposed, opening the doors for the mechanistic analysis including a potential $2 \mathrm{c}, 3 \mathrm{e}$ cyclization.

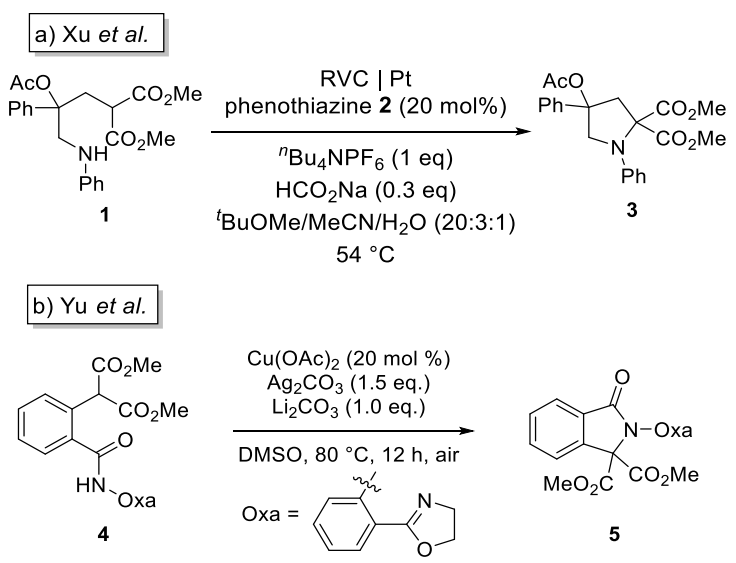

Figure 5. The selection of literature cyclization reactions which may proceed via eU. ${ }^{51,68}$

To evaluate competition between the two mechanistic pathways, we have chosen to explore the reaction energies for the cyclization performed by $\mathrm{Xu}$ et al. (Figure 5a). ${ }^{51}$ The reaction was performed under electrochemical conditions with phenothiazine $\mathbf{2}$ as an electron transfer mediator and sodium hydroxide (formed in situ) as a base.
A simplified model (6) of compound $\mathbf{1}$ devoid of the phenyl and the acetoxy group was chosen as a starting point for our computational analysis. We compared the change in Gibbs free energy of different possible reaction pathways (see ESI) and found three thermodynamically favorable paths (shown in different colors in Figure 6).

All three pathways start from a common sequence. After the initial deprotonation of 6 by hydroxide $\left(\Delta G=-32 \mathrm{kcal} \mathrm{mol}^{-1}\right)$, oxidation of the carbanion 7 by phenothiazine 2 radicalcation results in the formation of radical $8(\Delta G=$ $-36 \mathrm{kcal} \mathrm{mol}^{-1}$ ).

It is at this point that the reaction pathway diverges. The first (red) pathway is oxidation of the carbon-centered radical 8 to carbenium ion $9\left(\Delta G=-28 \mathrm{kcal} \mathrm{mol}{ }^{-1}\right)$. This step is thermodynamically feasible due to the use of a strong oxidant, the radical-cation of $2\left(E_{\mathrm{p} / 2}=\right.$ $0.52 \mathrm{~V}$ vs. SCE ${ }^{69}$ ). Once the cationic species 9 is formed, the intramolecular nucleophilic attack by the amine is favored $\left(-19 \mathrm{kcal} \mathrm{mol}^{-1}\right)$. Subsequent deprotonation to form the final product 14 is downhill by $-78 \mathrm{kcal} \mathrm{mol}^{-1}$.

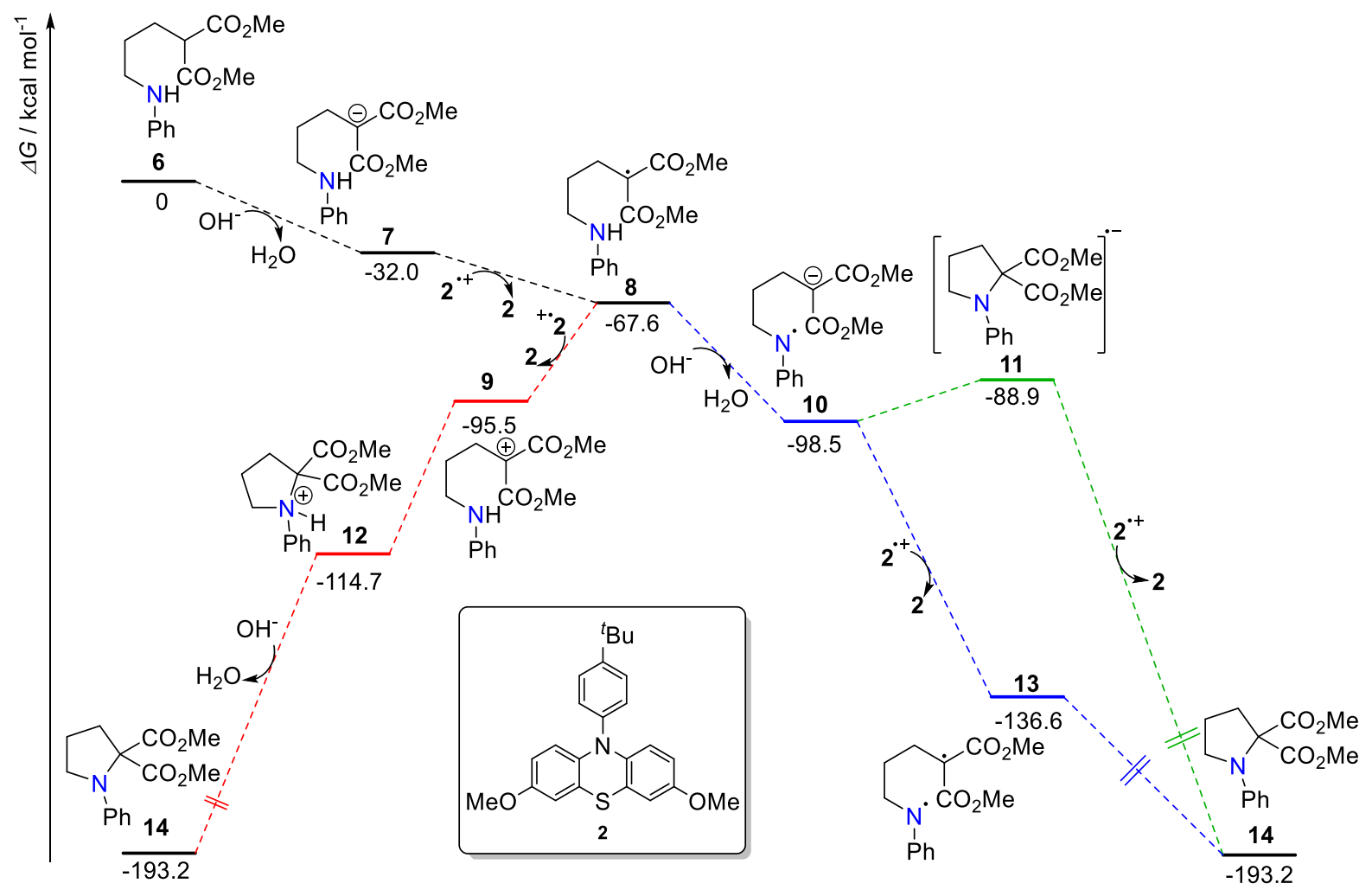

Figure 6. Change in free energy (in $\mathrm{kcal} \mathrm{mol}^{-1}$ ) starting from 6 for three different reaction pathways. Red pathway: Oxidation resulting in carbenium ion formation, followed by cyclization, and deprotonation. Blue pathway: Deprotonation, oxidation, resulting in diradical formation, followed by cyclization. Green pathway: Radical anion cyclization and oxidation of the upconverted electron. Calculations performed for $T=327.15 \mathrm{~K}$. 
The overall sequence of steps in the red pathway is the consecutive removal of $\mathrm{H}^{+} / \mathrm{e}^{-} / \mathrm{e}^{-}$ $/ \mathrm{H}^{+}$. The second oxidation has to proceed immediately after the first one, therefore requiring a sufficiently strong oxidant. Furthermore, the two sequential oxidations may require two separate oxidants to come into proximity to the reactant. When oxidants are present in low concentration, such sequential oxidation (while potentially thermodynamically favorable) may be slow. A portion of the electron transfer mediator will be present in the reduced form and unable to accept an electron. Additionally, oxidation of an anion is thermodynamically favored over the oxidation of a radical.

During the initial stages of the reaction, the concentration of anions will be higher than the concentration of radicals. As a result, it is more likely that an oxidant will come into proximity of an anion instead of a radical. Of course, the likelihood of an oxidant coming into proximity to a radical may increase as the concentration of anions dwindles and the concentration of radicals grows. However, radicals are often less persistent than anions. Hence, instead of patiently waiting for an oxidant to take an electron, they may undergo alternative reactions.

The second (blue) pathway proceeds via $\mathrm{N}-\mathrm{H}$ deprotonation of $\mathbf{8}$ with the in situ-generated hydroxide anion to form the acyclic radical anionic species 10. Such deprotonation is even more thermodynamically favorable under these reaction conditions $\left(\Delta G=-31 \mathrm{kcal} \mathrm{mol}^{-1}\right)$ than the formation of carbenium ion $9(\Delta G=-27 \mathrm{kcal}$ $\mathrm{mol}^{-1}$ ). Additionally, the base is constantly regenerated under these electrochemical conditions. As a result, the concentration of base should be higher than the combined concentration of $2 / 2^{++}$catalytic pair. Upon formation of the acyclic radical anion, all that is needed to reach the final product is a oneelectron oxidation and $\mathrm{C}-\mathrm{N}$ bond formation (cyclization). The two subsequent (blue and green) pathways are different in the order of these steps.

Continuing along the blue path, a direct oxidation of 10 by another molecule of $2^{\text {++ }}$ gives rise to a biradical 13 which can be formed either as a singlet or a triplet $\left(\Delta G=-38 \mathrm{kcal} \mathrm{mol}^{-1}\right.$ for the triplet product). If the triplet is formed, the diradical has to undergo intersystem crossing (ISC) into a singlet diradical with a subsequent highly favorable radical-radical recombination
$\left(\Delta G=-56 \mathrm{kcal} \mathrm{mol}^{-1}\right)$ that yields the final product 14 .

In the absence of a strong external oxidant, the radical anion 10 can follow the final (green) pathway. In this scenario, the cyclization proceeds first to form the cyclic radical anionic species 11. Although this step is mildly endergonic $\left(\Delta G=+9.6 \mathrm{kcal} \mathrm{mol}^{-1}\right)$, the sequential oxidation of the upconverted electron via $2^{\cdot+}$ is highly favored $\left(\Delta G=-104 \mathrm{kcal} \mathrm{mol}^{-1}\right)$.

This last reaction pathway is intriguing as it provides the most exergonic oxidation. Removing the upconverted electron is a staggering $76 \mathrm{kcal} \mathrm{mol}^{-1}$ more favorable than carbenium ion formation and $66 \mathrm{kcal} \mathrm{mol}^{-1}$ more favorable than formation of a triplet biradical. Additionally, the oxidations to form the carbenium ion 9 and diradical 13 are only favorable because a strong oxidant is used. In the absence of such an oxidant, these reactive intermediates may not form (vide infra). Utilizing such potent oxidants opens the door for undesired oxidation processes, possibly leading to side reactions. Conversely, oxidation of the upconverted electron becomes the only viable pathway in the absence of a strong oxidizing agent (Figure 7). For further insight into the mechanism, we continued our studies with a weaker oxidant, molecular oxygen, and by searching for possible transition states for the cyclization steps.

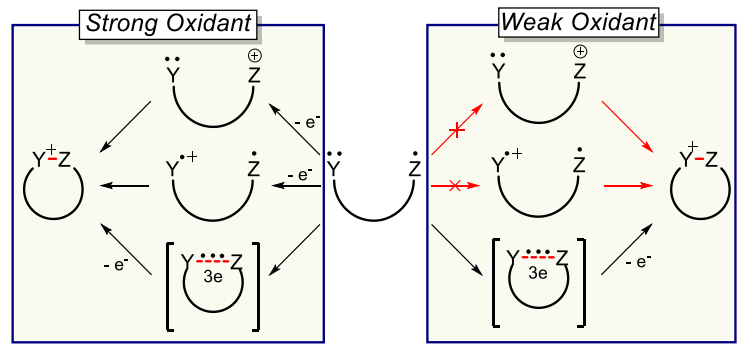

Figure 7. Left: A strong oxidant may be used to form two-electron bonds (via carbenium ions/diradicals) or may be used to oxidize an upconverted electron. Right: Utilizing a weak oxidant shuts down the pathways for a two-electron bond. Oxidation of an upconverted electron is still possible.

\section{Achieving selectivity via a three-electron path}

The qualitative scenarios suggested above were confirmed by computational data. An illustrative comparison for the formation of a radical, carbenium ion, and diradical via oxidation using $\mathbf{2}^{++}$and $\mathrm{O}_{2}$ as alternative oxidants is given in Figure 8. 
While previously favorable with $\mathbf{2}^{\mathbf{}}$, the use of $\mathrm{O}_{2}$ as an oxidant makes the oxidation of the carbanion 7 to a carbon-centered radical unfavorable by $26 \mathrm{kcal} \mathrm{mol}^{-1}$. In the absence of a strong oxidant, the oxidation of the carbon radical $\mathbf{8}$ to form carbenium ion $\mathbf{9}$ is even more uphill $\left(67 \mathrm{kcal} \mathrm{mol}^{-1}\right)$. An important alternative to consider is the possible oxidation of acyclic radical anion $\mathbf{1 0}$ to form diradical 13. However, the calculated free energy of the oxidation of $\mathbf{1 0}$ with molecular oxygen to the corresponding biradical (triplet) is still highly unfavorable (25 $\mathrm{kcal} \mathrm{mol}^{-1}$ ). This rather gloomy thermodynamic landscape renders the highly exergonic electron transfer from the cyclic radical anion of $\mathbf{1 1}$ to the oxidant $\mathrm{O}_{2}\left(\Delta G=-40 \mathrm{kcal} \mathrm{mol}^{-1}\right)$ especially striking! The contrast in the reducing power between the upconverted cyclic radical anion 11 and the distonic acyclic radical anion 10 is dramatic ( $\sim 65 \mathrm{kcal} \mathrm{mol}^{-1}$ difference)!

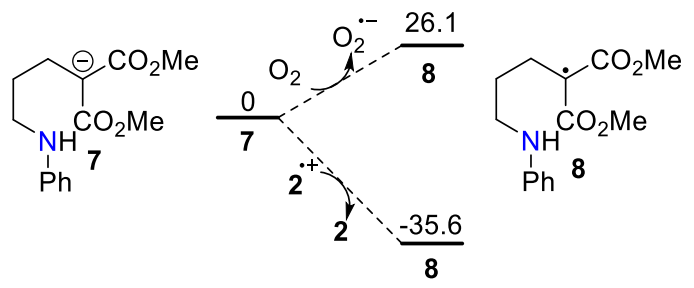<smiles></smiles>

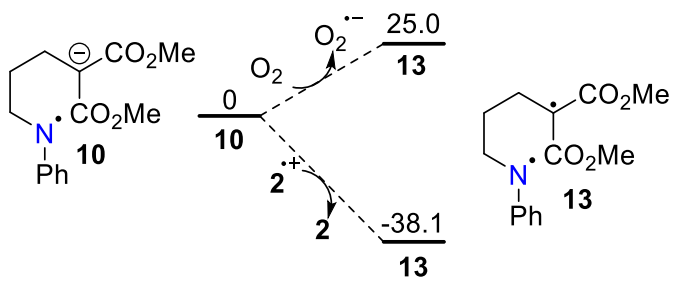

The only path possible when $\mathrm{O}_{2}$ is used as oxidant

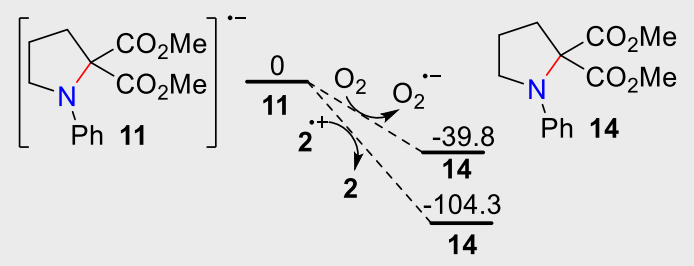

Figure 8. Direct comparison of oxidation steps between $2^{*+}$ and $\mathrm{O}_{2}$ as oxidants. All energies reported in $\mathrm{kcal} \mathrm{mol}^{-1}$.
In summary, when $\mathrm{O}_{2}$ is used as an oxidant, only the $3 e$-path is thermodynamically viable.

An interesting difference from the earlier $\mathrm{C}-\mathrm{N}$ bond formation described by Alabugin et al. in the present systems is that, instead of the reaction of a nitrogen anion with a carbon radical, the upconversion and the $\mathrm{C}-\mathrm{N}$ bond formation herein involve a carbanion and a nitrogen radical (Figure 9). However, this variation makes little, if any, conceptual difference for the outcome.

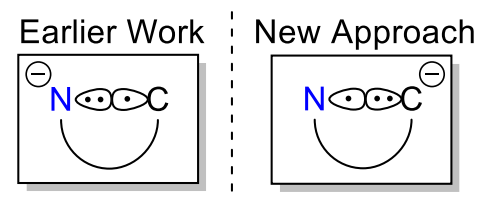

Figure 9. Left: Previously reported radical anion cyclization between nitrogen-anion and carbon radical. Right: An alternative approach to radical anion cyclization via carbanion and nitrogen-radical.

However, there is a question of whether this path will be kinetically accessible. In order to address this question, we have calculated representative activation barriers for such reactions. Such calculations are extremely interesting from a fundamental perspective because they provide insight into the electronic and steric effects for the formation of 3e-bonds, a fundamentally important but underutilized process.

\section{Solvent effect on the cyclization transition state}

First, we located the cyclization transition states starting from species 10 in water (TS1) and DMF (TS2). The activation barriers $\Delta G^{f}$ to TS1 of $17.9 \mathrm{kcal} \mathrm{mol}^{-1}$ and to TS2 of $12.9 \mathrm{kcal} \mathrm{mol}^{-1}$ correspond to half-lives $t_{1 / 2}$ of $1.5 \mathrm{~s}$ and $0.3 \mathrm{~ms}$ for species 10 in water and DMF, respectively. Half-lives are based on the Eyring equation (assuming the transmission coefficient to be unity $)^{70-72}$ and assuming first order reaction kinetics. The half-life of aniline radical 10 in water is sufficiently high to suggest the possibility of side reactions, e.g., cross couplings with other radicals. Considering that the cyclization in DMF is predicted to proceed -5000-times faster, we then shifted our focus to these reaction conditions, analogous to those used in the previous $\mathrm{C}-\mathrm{N}$ forming reactions of radical anions. ${ }^{30,31}$ 


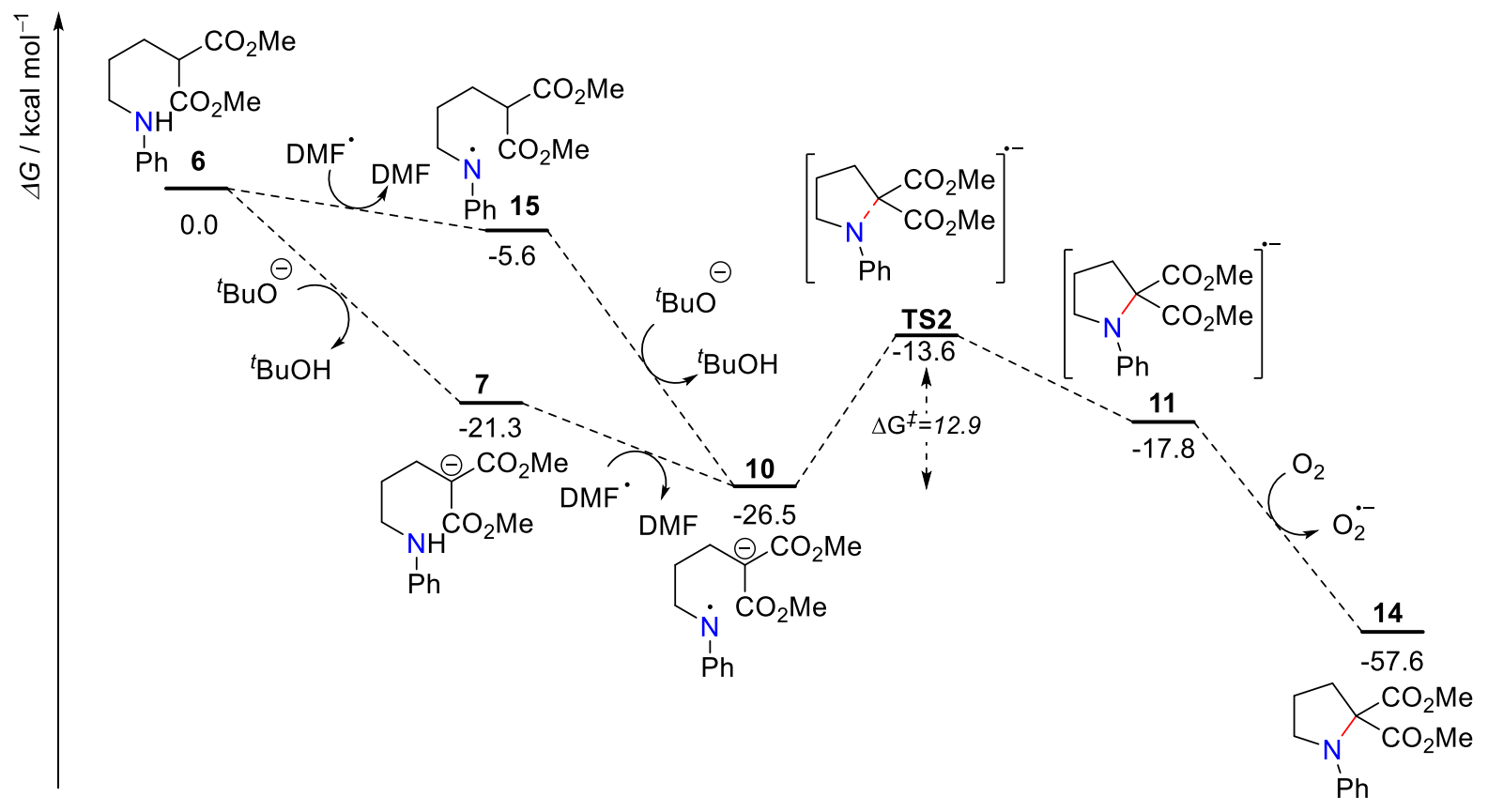

Figure 10. Changes in free energy when using tert-butoxide as a base, DMF radical as a hydrogen atom transfer reagent, and $\mathrm{O}_{2}$ as the oxidant ${ }^{30}(\mathrm{U}) \mathrm{M06}-2 \mathrm{X}(\mathrm{D} 3) / 6-31+\mathrm{G}(\mathrm{d}, \mathrm{p}) / \mathrm{SMD}=\mathrm{N}, \mathrm{N}$-dimethylformamide/ opt = tight.

\section{Full energy profile of the three-electron pathway}

The calculated energy profile of the full reaction under the above conditions is shown in Figure $10 .{ }^{30}$ In the first step, the deprotonation $(\Delta G=-$ $21 \mathrm{kcal} \mathrm{mol}^{-1}$ ) of the $\mathrm{C}-\mathrm{H}$ acidic dimethyl malonate $\left(p K_{a}=15.9 \text { in DMSO }\right)^{73}$ is favored over of the less acidic aniline $\left(\mathrm{p} K_{\mathrm{a}}=30.7\right.$ in DMSO). ${ }^{74}$ Following formation of carbanion 7 , hydrogen atom abstraction by a DMF radical ${ }^{30}$, ${ }^{31}$ allows for the formation of a nitrogen-centered radical $\left(\Delta G=-5.2 \mathrm{kcal} \mathrm{mol}^{-1}\right)$. The acyclic radical anion 10 can undergo an endothermic cyclization $\left(\Delta G=+8.7 \mathrm{kcal} \mathrm{mol}^{-1}\right)$ via TS2 with a relatively low activation barrier of $12.9 \mathrm{kcal}$ $\mathrm{mol}^{-1}$. The cyclic radical anion 11 can be readily oxidized by molecular oxygen to form the final

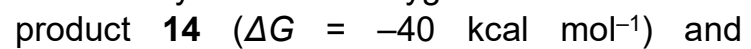
superoxide.

\section{Electronic structures}

To gain additional insight into why acyclic radical anion 10 is a weaker reductant than cyclic radical anion 11, it is illustrative to consider their respective molecular orbital energies (Figure 11) and to evaluate how well the simple model presented earlier for atomic orbitals (Figure 3 ) is transferrable to the more complex systems.

We found that the energetically highest alpha and beta electrons in $\mathbf{1 0}$ have an energy of 0.209 and -0.212 hartrees $\left(E_{\mathrm{h}}\right)$, respectively. HOMO-1 was found to only contain an alpha electron with an orbital energy of $-0.248 E_{h}$. Therefore, a HOMO-SOMO inversion is present in the acyclic radical anion 10..$^{75-79}$ On the other hand, radical anion 11 was found to have all of its orbitals destabilized (when compared to acyclic radical anion 10). The HOMO underwent notable destabilization and only contained a single (alpha) electron with an orbital energy of $-0.135 E_{\mathrm{h}}$ (a difference of $\sim 46 \mathrm{kcal} \mathrm{mol}^{-1}$ compared to the HOMO of 10). HOMO-1 contained both an alpha and a beta electron at -0.229 and $-0.227 E_{\mathrm{h}}$, respectively.

This direct comparison (Figure 11) provides some quantitative insight into the nature of electron upconversion. Both 10 and 11 are radical anions, the difference however is that the cyclic product $\mathbf{1 1}$ contains an electron in a high energy antibonding orbital. As a consequence, the molecular orbital containing this upconverted electron is raised in energy, rendering the reactant a more potent reducing agent. Meanwhile, 10 only contains electrons in lower lying non-bonding orbitals. As a result, the acyclic radical anion is a weaker reducing agent (compared to 11). 


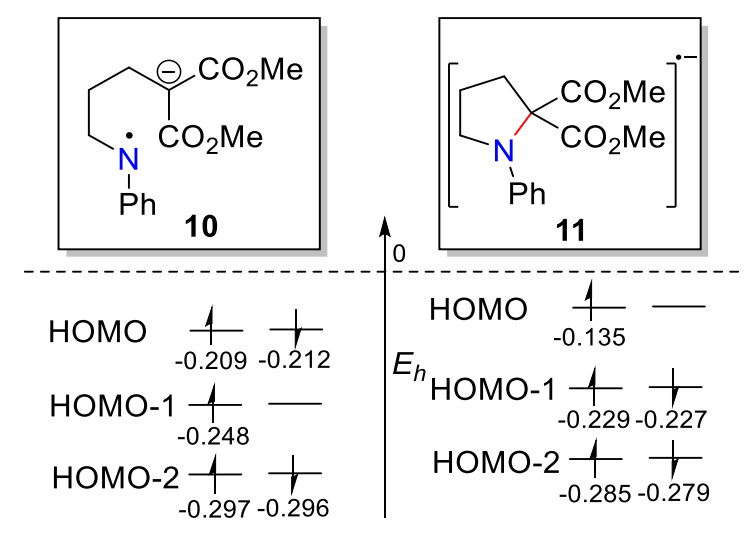

Figure 11. Molecular orbital energies in hartree $\left(E_{h}\right)$ for acyclic and cyclic radical anions 10 and 11.

\section{Flow of spin density during the cyclization}

The evolution of spin density (blue) throughout the cyclization (Figure 12a) reveals the change in localization of the unpaired electron. In 10, spin density is located on the nitrogen and the aromatic ring. In TS2, spin density shifts to nitrogen and one of the ester carbonyl groups. Specifically, spin density is located in the carbonyl group with $\pi$ orbitals that are parallel to the $\mathrm{C}-\mathrm{N}$ bond being formed. Meanwhile, the carbonyl with a m orbital that is orthogonal to the newly formed $\mathrm{C}-\mathrm{N}$ bond does not participate in spin delocalization.

In the cyclized species 11, the entire spin density is located at the carbonyl group, the $\pi$ orbital of which was parallel to the newly formed $\mathrm{C}-\mathrm{N}$ bond in TS2, producing a ketyl radical analogue. Accordingly, the SOMO of $\mathbf{1 1}$ has a strong contribution from the carbonyl group. In other words, the upconverted electron resides in a $\pi^{*}$ orbital of one of the ester groups.

The spin density was also compared to the spin densities obtained from CAS $(3,3)$ and DLPNO$\operatorname{CCSD}(T)$ single point calculations and found to be in agreement.

Figure $12 \mathrm{~b}$ shows a graphical representation of TS2 including each bond length. The relatively long internuclear distance of the forming $\mathrm{C}-\mathrm{N}$ bond $(1.69 \AA)$ indicates a late, product-like, TS for this endergonic step. An animation of the cyclization can be found as supplementary information.

Interestingly, the $\mathrm{C}(5)-\mathrm{C}(6)$ bond towards the carbonyl group participating in spin delocalization is shorter than the $C(5)-C(10)$ bond, the ester of which does not contain spin density. Conversely, the $\mathrm{C}(6)-\mathrm{O}(8)$ and $C(6)=O(7)$ bonds in the ester that contains the radical are longer than their counterpart in the "bystander" ester.

The difference in the bond length further illustrates that only one of the two esters participates in delocalization of the extra electron. The m-system of the "bystander" ester is orthogonal to the incipient $\mathrm{C} \cdots \mathrm{N}$ bond and is stereoelectronically inactive in radical stabilization. In contrast, the second ester is stereoelectronically activated by rotation which aligns it with the forming $\mathrm{C}-\mathrm{N}$ bond. As result, its carbonyl moiety participates in an allylic type delocalization of spin density at the $\alpha$-carbon (Figure 12c).
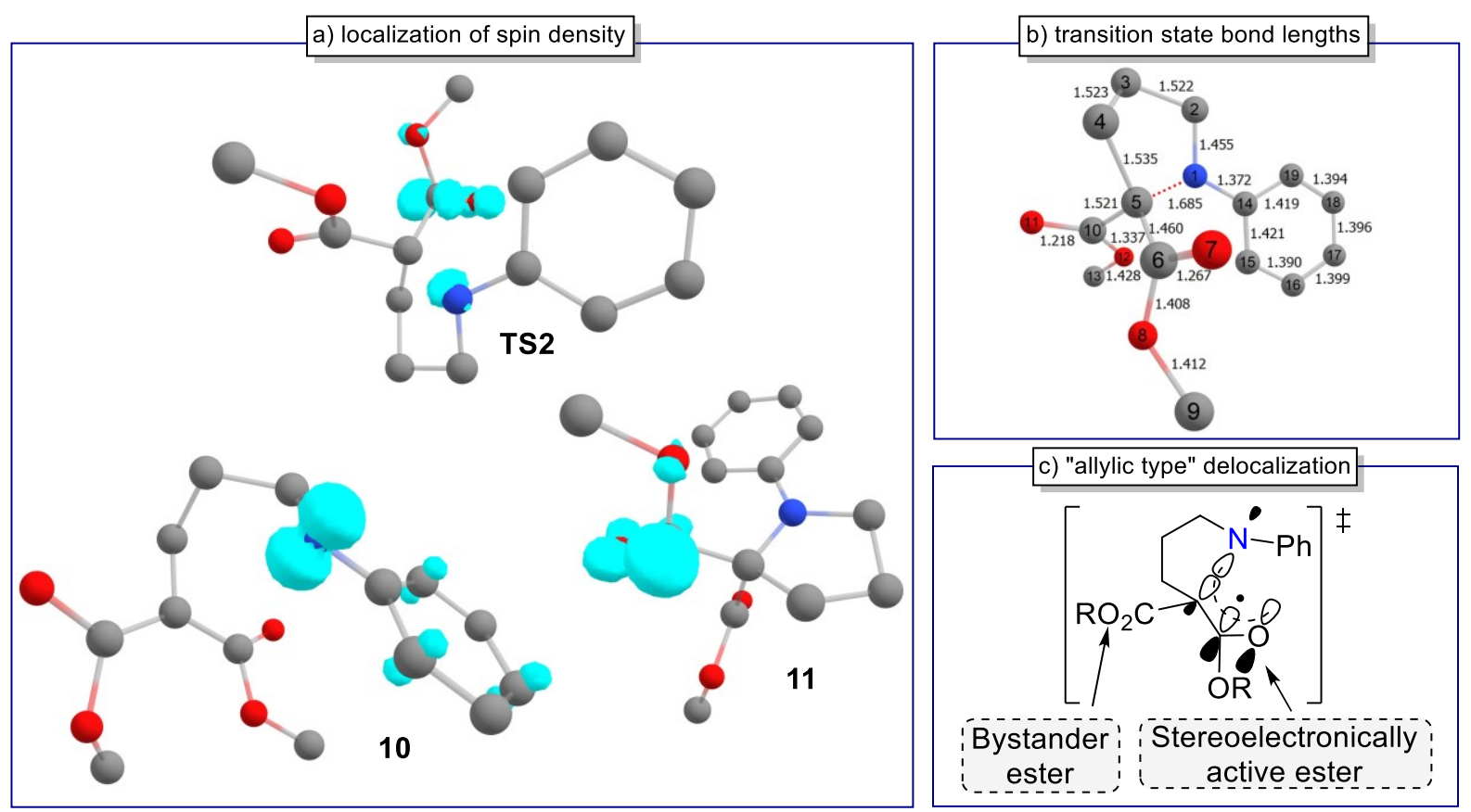
Figure 12. a) Spin density (blue) plot obtained from DFT calculations of 10, TS2, and 11. Contour value: 0.02. Hydrogen atoms are omitted for clarity. b) Bond lengths for each atom in TS2, hydrogen atoms are omitted for clarity. c) Allylic type spin delocalization in TS2. Only one ester is activated and participates in spin delocalization, the second acts only as a bystander.

\section{Substitution effects on the free energy of the cyclization}

To evaluate the effect of substituents, the reaction energies of the cyclization of radical anions related to 10 were calculated.

Depending on the substituents on the $\delta$-carbon and on nitrogen, two different electron arrangements (i.e., the preferred resonance structures 16 and 17) were found (Figure 13). The HOMO-SOMO inversion mentioned in Figure 11 depends on the nature of the substituents.<smiles>CN(CCCCNc1ccccc1)[W]=O</smiles>

16

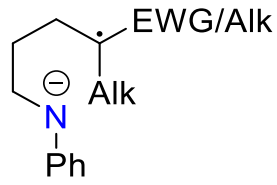

17
Figure 13. Effects of substituents on the preferred electron arrangements in acyclic radical anions.

Electron withdrawing groups (EWGs) at the $\delta$ carbon favor the carbanion 16, whereas alkyl groups (Alk) or a combination of one EWG and one alkyl group (e.g., 17a-e) favor 17. When considering dimethyl malonate and varying the $\mathrm{N}$-substituent, an electron distribution similar to 16 was mostly observed.

As shown in Table 1, the reaction free energies are only negative for two entries (7 and 8 ), which have two different substituents at the reacting carbon atom. Changes in reaction enthalpy in Table 1 are largely dependent upon the relative abilities of $R^{1}$ and $R^{2}$ to stabilize the carbanion in the reactant and the extra electron in the product. For instance, in the model substrate 10, the two ester groups in the $\left(\mathrm{CO}_{2} \mathrm{Me}\right)_{2} \mathrm{CH}_{2}\left(\mathrm{pK} \mathrm{a}=15.9^{80}\right.$, DMSO $)$ moiety can provide synergistic stabilization to its conjugate base. However, communication between the two carbonyls is broken in both the transition state and the product where the extra electron resides in only one of the carbonyl groups (Figure 12). In this scenario, presence of two EWGs leads to unproductive and excessive reactant stabilization.

Table 1. Enthalpy and free energy for cyclization reactions of 16. All energies reported in kcal mol-1

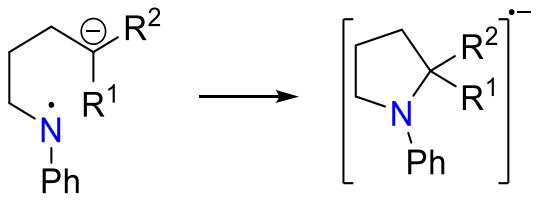

16

18

\begin{tabular}{|c|c|c|c|c|c|}
\hline \# & Substituent & 16 & 18 & $\Delta H$ & $\Delta G$ \\
\hline 1 & $\mathrm{R}^{1}=\mathrm{R}^{2}=\mathrm{COMe}$ & $\mathbf{a}$ & $\mathbf{a}$ & 14.0 & 16.2 \\
\hline 2 & $\mathrm{R}^{1}=\mathrm{R}^{2}=\mathrm{CO}_{2} \mathrm{Me}$ & 10 & 11 & 8.6 & 8.6 \\
\hline 3 & $\mathrm{R}^{1}=\mathrm{R}^{2}=\mathrm{CO}_{2} \mathrm{Et}$ & b & b & 9.0 & 9.4 \\
\hline 4 & $\mathrm{R}^{1}=\mathrm{R}^{2}=\mathrm{CO}_{2} \mathrm{Pr}$ & c & c & 9.4 & 10.0 \\
\hline 5 & $\mathrm{R}^{1}=\mathrm{R}^{2}=\mathrm{CO}_{2}{ }^{t} \mathrm{Bu}$ & d & d & 11.8 & 12.8 \\
\hline 6 & $\mathrm{R}^{1}=\mathrm{R}^{2}=\mathrm{CO}_{2} \mathrm{CF}_{3}$ & e & e & 10.4 & 13.0 \\
\hline 7 & $\begin{array}{l}\mathrm{R}^{1}=\mathrm{CO}_{2} \mathrm{Me} \\
\mathrm{R}^{2}=\mathrm{CO}_{2} \mathrm{CF}_{3}\end{array}$ & $\mathbf{f}$ & f & -1.2 & -0.1 \\
\hline 8 & $\begin{array}{l}\mathrm{R}^{1}=\mathrm{CO}_{2} \mathrm{Me} \\
\mathrm{R}^{2}=\mathrm{H}\end{array}$ & $\mathbf{g}$ & g & -2.6 & -1.7 \\
\hline
\end{tabular}

If one of the ester groups is removed (as seen in entry 8), the reactant carbanion is less stabilized $\left(\mathrm{CH}_{3} \mathrm{CO}_{2} \mathrm{Et}: \mathrm{pK}\right.$ removing unproductive reactant stabilization, more favorable reactions can be designed $(\Delta H$ $=8.6 \mathrm{kcal} \mathrm{mol}^{-1}$ vs. $\left.\Delta H=-2.6 \mathrm{kcal} \mathrm{mol}^{-1}\right)$.

A similar effect can be achieved when one of the EWGs is a much stronger acceptor than the other (i.e., $\mathrm{R}^{1}=\mathrm{CO}_{2} \mathrm{Me}, \mathrm{R}^{2}=\mathrm{CO}_{2} \mathrm{CF}_{3}$, entry 7 ). In this situation, the trifluoro-substituted group plays a dominant role in stabilizing both the reactant and the product. Hence, the loss of contribution from the less important $\mathrm{CO}_{2} \mathrm{Me}$ substituent in stabilizing the negative charge along the reaction path is less penalizing.

The consequences of over-stabilizing the conjugate base can additionally be seen in entries 1 and 2 . When the two ester groups $R^{1}$ and $R^{2}$ are swapped for the stronger ketone $\mathrm{C}(\mathrm{O}) \mathrm{Me}$ acceptors $\left(\mathrm{p} K_{\mathrm{a}}=13.3^{82}\right)$, the reaction becomes even less favorable $(\Delta H=14.0 \mathrm{kcal}$ $\mathrm{mol}^{-1}$ ).

Entries 2-5 show that the size and steric effects of alkyl groups in the ester moiety impact reactivity. When $R^{1}=R^{2}=C_{2} R$, an increase in the size of $\mathrm{R}$ from $\mathrm{Me} \rightarrow \mathrm{Et} \rightarrow{ }^{i} \mathrm{Pr} \rightarrow{ }^{\mathrm{t}} \mathrm{Bu}$ results in a decrease in reaction favorability $(\Delta H=8.6$, $9.0,9.4$, and $11.8 \mathrm{kcal} \mathrm{mol}^{-1}$, respectively).

For the reactants in both Tables 2 and 3, the preferred localization of the radical moves from nitrogen to carbon and, hence, the negative charge is localized on nitrogen (Figure 13). 
In Table 2, entries $1\left(R^{1}=\right.$ COMe, $\left.R^{2}=H\right)$ and 2 $\left(R^{1}=\right.$ COMe, $\left.R^{2}=M e\right)$, additionally show that moving from a less stable (secondary) to a more stable (tertiary) radical adds a thermodynamic penalty $\left(\Delta H=0.1 \mathrm{kcal} \mathrm{mol}^{-1} \mathrm{vs} . \Delta H=2.9 \mathrm{kcal}\right.$ $\left.\mathrm{mol}^{-1}\right)$. Entries 3-5 $\left(\mathrm{R}^{1}=\mathrm{CO}_{2} \mathrm{Me}, \mathrm{R}^{2}=\mathrm{Me}\right.$, Et, $\left.{ }^{t} \mathrm{Bu}\right)$ continue to show that increasing the size and steric of alkyl groups near the reactive centers further increases the reaction enthalpy. Finally, the cyclic radical anion $\mathbf{1 8 m}$ is different from previous examples in that the upconverted electron is additionally delocalized over the aromatic system of the pendant phenyl group $\left(R^{2}\right)$ in the cyclic product providing some additional stabilization in comparison to the unsubstituted analog 11.

Table 2. Enthalpy and free energy for cyclization reactions of 18. $R^{1}$ and $R^{2}$ participate in stabilization of both reactant and product. All energies reported in kcal mol-1

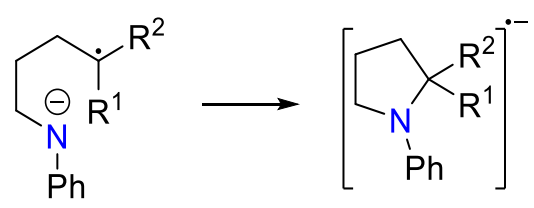

17

18

\begin{tabular}{|c|c|c|c|c|c|}
\hline \# & Substituent & 17 & 18 & $\Delta H$ & $\Delta G$ \\
\hline 1 & $\begin{array}{l}\mathrm{R}^{1}=\mathrm{COMe} \\
\mathrm{R}^{2}=\mathrm{H}\end{array}$ & $\mathbf{a}$ & h & 0.1 & 0.1 \\
\hline 2 & $\begin{array}{l}\mathrm{R}^{1}=\mathrm{COMe} \\
\mathrm{R}^{2}=\mathrm{Me}\end{array}$ & b & i & 2.9 & 5.6 \\
\hline 3 & $\begin{array}{l}\mathrm{R}^{1}=\mathrm{CO}_{2} \mathrm{Me} \\
\mathrm{R}^{2}=\mathrm{Me}\end{array}$ & c & j & 7.5 & 10.2 \\
\hline 4 & $\begin{array}{l}\mathrm{R}^{1}=\mathrm{CO}_{2} \mathrm{Me} \\
\mathrm{R}^{2}=\mathrm{Et}\end{array}$ & d & k & 8.4 & 8.9 \\
\hline 5 & $\begin{array}{l}\mathrm{R}^{1}=\mathrm{CO}_{2} \mathrm{Me} \\
\mathrm{R}^{2}={ }^{t} \mathrm{Bu}\end{array}$ & e & I & 12.2 & 13.1 \\
\hline 6 & $\begin{array}{l}\mathrm{R}^{1}=\mathrm{CO}_{2} \mathrm{Me} \\
\mathrm{R}^{2}=\mathrm{Ph}\end{array}$ & f & m & 5.5 & 7.4 \\
\hline
\end{tabular}

In Table 3, $\mathrm{R}^{1}$ and $\mathrm{R}^{2}$ provide direct stabilization for the radical in the reactant but not the product. Entry 1 is the most favored cyclization $\left(\Delta H=0.2 \mathrm{kcal} \mathrm{mol}^{-1}\right)$ as it starts from the least stabilized primary radical. The cyclization of a more stable tertiary carbon radical $\left(\mathrm{R}^{1}=\mathrm{R}^{2}=\right.$ $\mathrm{Me})$ is less favorable $\left(\Delta H=0.9 \mathrm{kcal} \mathrm{mol}^{-1}\right)$.
Similar to what was observed in Table 1 , an increase in alkyl group size continuously renders the cyclization more endergonic as it provides additional radical stabilization in the reactant (through hyperconjugation) and destabilizes the product by steric effects.

Table 3. Enthalpy and free energy for cyclization reactions of 18. $R^{1}$ and $R^{2}$ only participate in stabilization of reactant. All energies reported in $\mathrm{kcal}$ $\mathrm{mol}^{-1}$

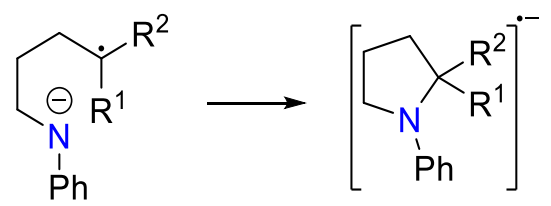

\section{7}

\begin{tabular}{clcccc}
\hline$\#$ & Substituent & $\mathbf{1 7}$ & $\mathbf{1 8}$ & $\Delta H$ & $\Delta G$ \\
1 & $\mathrm{R}^{1}=\mathrm{R}^{2}=\mathrm{H}$ & $\mathbf{g}$ & $\mathbf{n}$ & 0.2 & 1.1 \\
2 & $\mathrm{R}^{1}=\mathrm{R}^{2}=\mathrm{Me}$ & $\mathbf{h}$ & $\mathbf{0}$ & 0.9 & 4.3 \\
3 & $\mathrm{R}^{1}=\mathrm{Et}$ & $\mathbf{i}$ & $\mathbf{p}$ & 3.3 & 7.2 \\
& $\mathrm{R}^{2}=\mathrm{Me}$ & & & & \\
4 & $\mathrm{R}^{1}={ }^{t} \mathrm{Bu}$ & $\mathbf{j}$ & $\mathbf{q}$ & 6.7 & 9.7 \\
& $\mathrm{R}^{2}=\mathrm{Me}$ & $\mathbf{k}$ & $\mathbf{r}$ & 16.2 & 19.0 \\
5 & $\mathrm{R}^{1}=\mathrm{R}^{2}={ }^{t} \mathrm{Bu}$ & $\mathbf{k}$ & & & \\
\hline
\end{tabular}

Figure 14 shows the change in enthalpy for the cyclization of different $\mathrm{N}$-aryl reactants 19 to the cyclic radical anions $\mathbf{2 0}$ versus the Hammet parameter $\sigma^{+}$of the related $\mathrm{N}$-substituent. We explored a total of 23 aromatic rings substituents Hammett sigma constants ${ }^{83,84}$ and found them to show a good correlation with the change in reaction enthalpy $\left(R^{2}=0.89\right)$. We found that reactions with EWGs on the $\mathrm{N}$-aryl group mold the reaction more energetically favored. Thus, a more electron deficient nitrogen center favors the cyclization. Electron donating groups (EDGs) have a less deactivating effect at the meta- than at the paraposition. In contrast, EWGs favor the para- over the meta-position. In other words, EDG and EWGs favor positions which (through an inductive effect) lower electron density at the nitrogen-radical. 


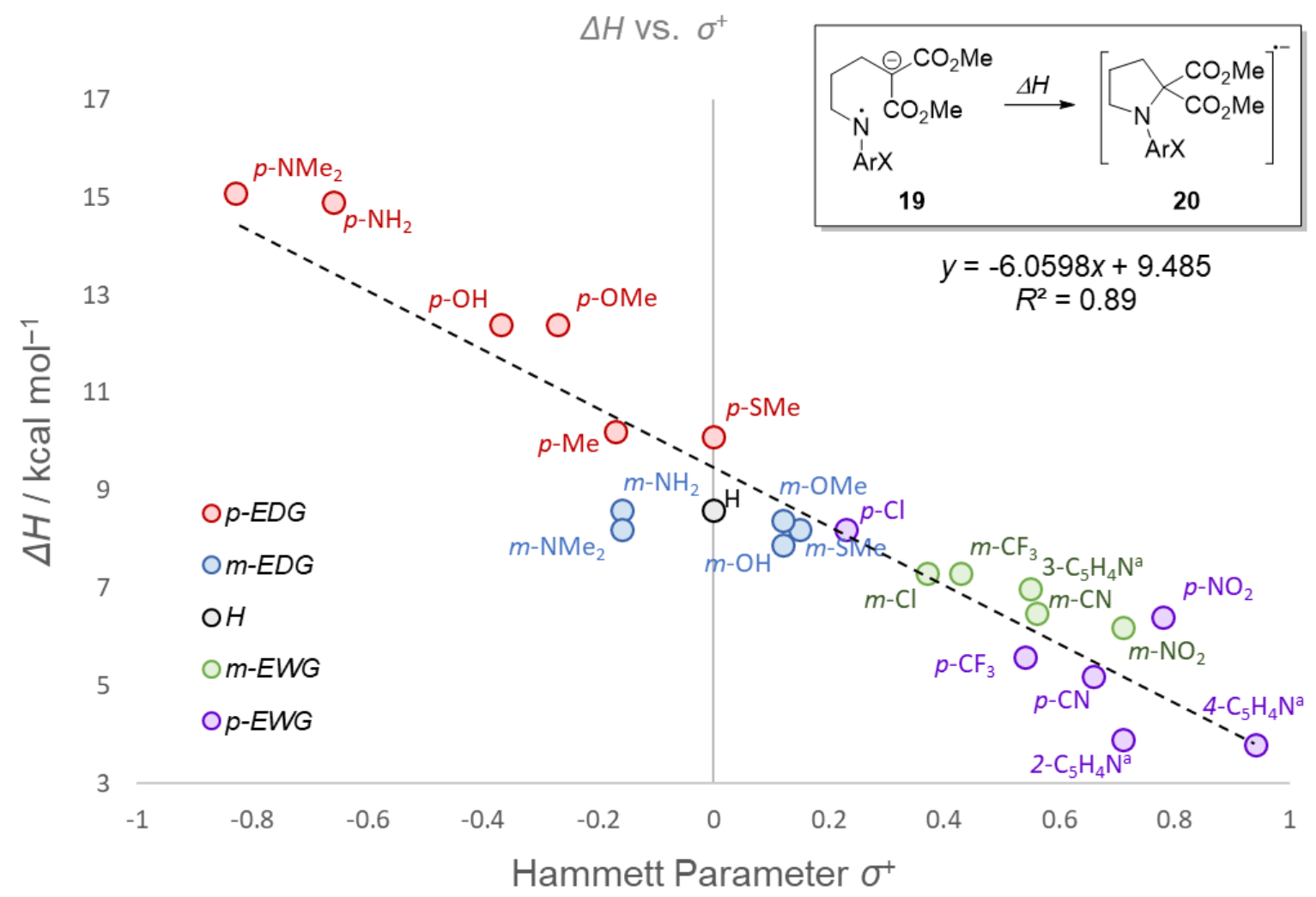

Figure 14. Plot of Hammett parameters vs. $\Delta H$ in kcal mol${ }^{-1}$ for the conversion of compound 19 to 20 . A total of 23 different aromatic rings were analyzed. The para and meta electron withdrawing groups are presented in purple and green, respectively. The para and meta electron donating groups are presented in blue and red, respectively. ${ }^{a}$ The Ar group is pyridine (2-, 3, or 4-Py) and not a phenyl ring with a pyridyl substituent.

\section{Exploratory transition states}

In addition to the thermochemical data depicted thus far, further radical anionic transition states have been identified and are shown in Table 4. The same trends observed for the thermochemical data apply to the activation free energies. EWGs lower the activation barrier while steric hindrance on the reacting centers leads to an increase. The $\mathrm{N}$-phenyl moiety leans to the same side as the ester group, where the spin density is located. This observation can be seen for transition states TS2-5, In the absence of any EWGs transition state energies are further destabilized TS6-8. The broad range of the incipient $\mathrm{C}-\mathrm{N}$ distances $\left(r_{\mathrm{C}-\mathrm{N}}\right)$ indicate the $\mathrm{C}-\mathrm{N}$ bond to be sensitive to the strength and the number of acceptors.

\section{Outlook}

The potential utility of hidden 3e-pathways extends to cascades where such pathways are coupled with other reactions. For example, MacMillan and coworkers described an elegant method for combining aldehydes and alkenes to generate pyrrolidines (Figure 15).${ }^{14}$ Here, the
$\mathrm{C}-\mathrm{N}$ bond formation is the final step in the stereospecific formation of pyrrolidine-3carbaldehydes starting from a transient enamine and an olefin.

The authors suggest a plausible mechanism where, after the in situ formation of the enamine 21', oxidation forms a nitrogen radical-cation 22. This intermediate adds to an alkene to produce a distonic radical-cation 23 with a separated carbon radical and an iminium cation center. The newly formed carbon radical is proposed to be oxidized to carbenium ion 24 . The carbenium ion is captured by the pendant nitrogen nucleophile to form the $\mathrm{C}-\mathrm{N}$ bond of the pyrrolidine core.

However, one can envision an alternative pathway for the key cyclization step. When considering the oxidation of a cationic molecule (such as 23) vs. its neutral counterpart, one can anticipate that the cation would be harder to oxidize ${ }^{85,86}$ Note that the proposed oxidation of distonic radical-cation $\mathbf{2 3}$ would form a dication (the carbenium ion 24). 
Table 4. Calculated radical anionic transition states. All energies reported in $\mathrm{kcal} \mathrm{mol}^{-1}$

\begin{tabular}{|c|c|c|c|}
\hline TS structure & $\Delta G^{f}$ & $\Delta G$ & $r_{C-N} / \AA$ \\
\hline$\left[\begin{array}{c}\mathrm{N}_{\mathrm{Ph}}^{\prime} \mathrm{CO}_{2} \mathrm{Me} \\
\mathrm{TS}\end{array}\right]$ & 12.9 & 8.6 & 1.7 \\
\hline$\left[\underset{\mathrm{Ph}}{\mathrm{N}^{\prime}} \mathrm{CO}_{2} \mathrm{CF}_{3}\right.$ & 11.2 & -0.1 & 1.8 \\
\hline
\end{tabular}

TS3
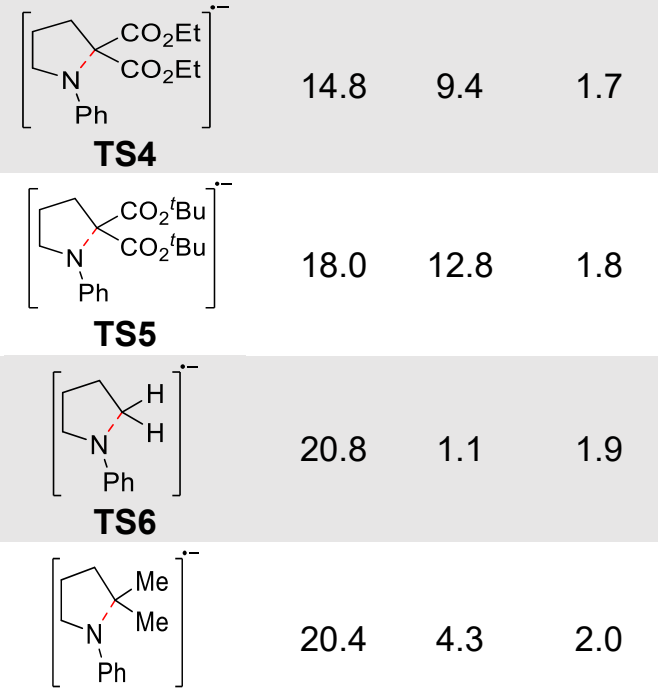

$20.4 \quad 4.3 \quad 2.0$

TS7

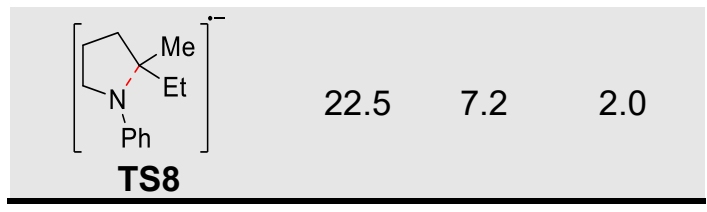

On the other hand, the difficult oxidation of the radical-cation 23 can be bypassed if one could trap the carbon radical via formation of a $2 \mathrm{c}, 3 \mathrm{e}$ bond with the nitrogen lone pair in the $N$ deprotonated intermediate 24' (neutral but shown as a zwitter-ionic resonance structure in Figure 15). The resulting upconverted neutral radical product 24 " would be easier to oxidize than the cation 23. In fact, it is possible that the $\mathrm{N}-\mathrm{H}$ bond of the sulfonamide (pro)nucleophile would be already deprotonated under the reaction conditions well before to the cyclization step. ${ }^{30,87,88}$

Furthermore, these mechanistic questions are not limited to $\mathrm{C}-\mathrm{N}$ bond formation but can also involve the processes that create other bond types via radical/polar cross-over scenarios. The examples of radical addition to heteroarenes ${ }^{89-92}$ and the synthesis of coumarin $^{93-98}$ in photoreactions show how it can apply to the formation of $\mathrm{C}-\mathrm{C}$ bonds as well (Figure 16).
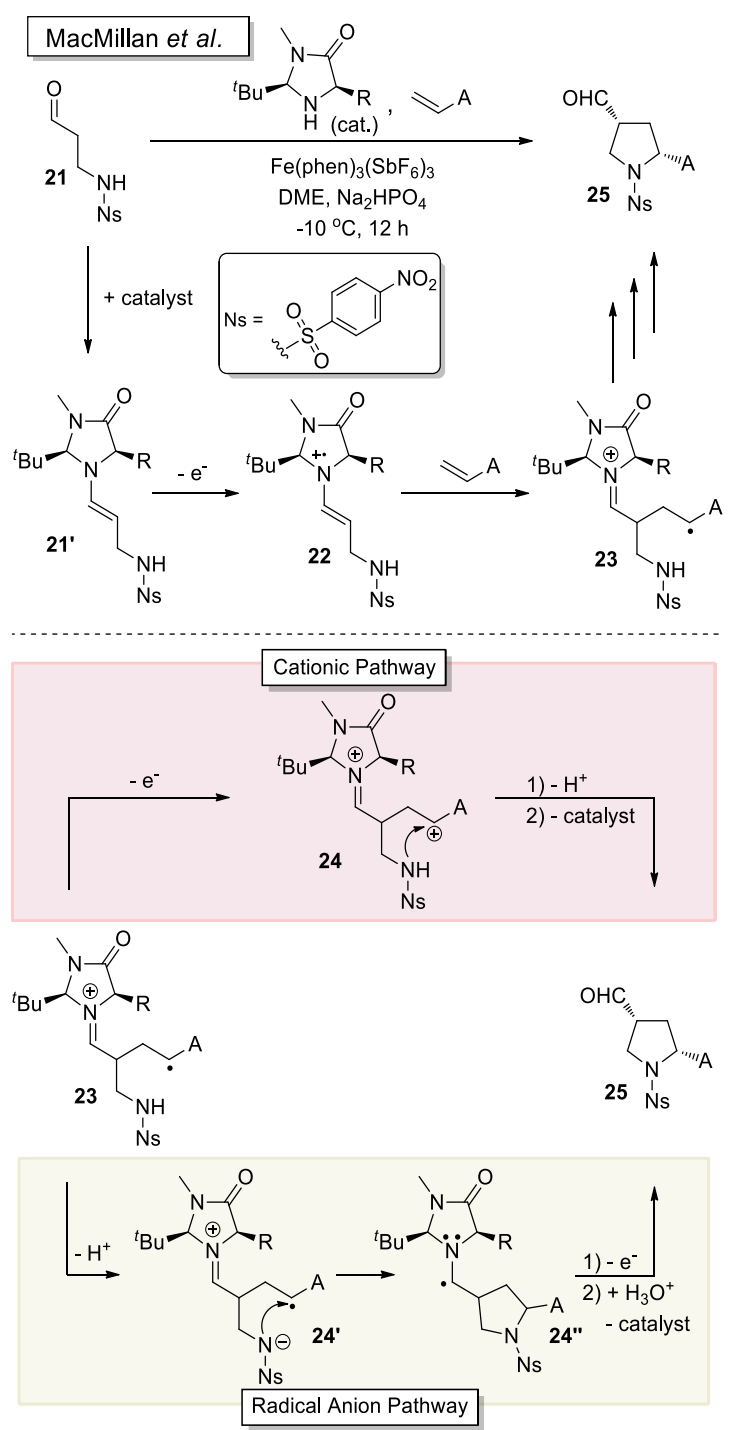

Figure 15. Top: Proposed mechanistic pathway for the conversion of aldehydes and alkenes into pyrrolidines. Bottom: Possible deprotonationmediated cyclization pathways.

Commonly, photocatalytic cycles involving radical addition to heteroarenes are initiated by promoting the photocatalyst (PC) to an excited state. Subsequently, the PC injects an electron into an $\mathrm{R}-\mathrm{Y}$ bond resulting in the formation of a $\mathrm{Y}$-anion and an $\mathrm{R}$-radical. The $\mathrm{R}$-radical adds to the $\pi$-system of the heteroarene $\mathbf{2 6}$ resulting in the formation of resonance-stabilized radical 27. The next commonly proposed step is the oxidation of the newly formed radical and the reduction of the $\mathrm{PC}$. The result is the formation of carbenium ion $\mathbf{2 8}$ and the regeneration of the $\mathrm{PC}$, thus completing the catalytic cycle. After formation of a cation, the loss of a proton restores aromaticity and yields the final product 29. 
A similar sequence can be suggested for the synthesis of coumarins from phenyl propiolates 30. Under photocatalytic conditions, the excited $P C$ initiates the reaction via reduction of an $R-Y$ bond. The newly formed R-radical then attacks the triple bond to initiate a 6-exo-dig cyclization that forms carbon radical 31. Subsequent oxidation of the carbon radical forms carbenium ion 32 which can be deprotonated to restore aromaticity in $\mathbf{3 3}$.
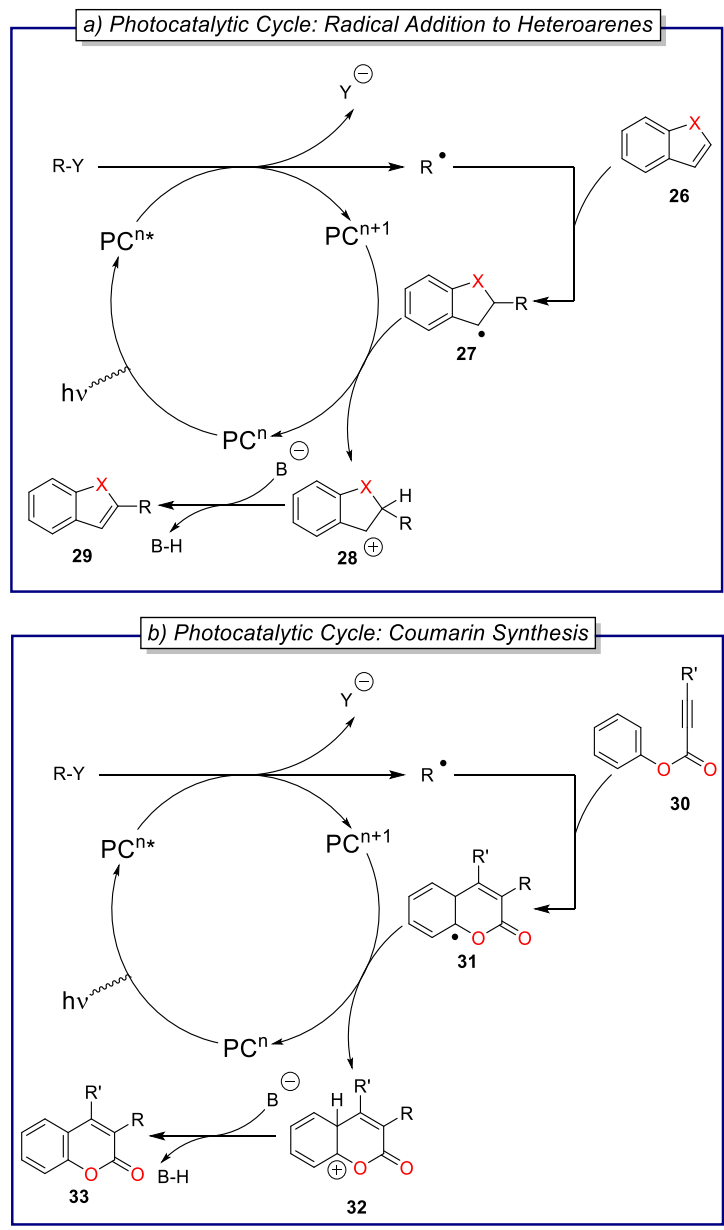

Figure 16. a) A commonly proposed photocatalytic cycle for radical addition into heteroarenes. b) $A$ commonly proposed photocatalytic cycle for the transformation of phenyl propiolates into coumarin derivatives.

Considering the photocatalytic cycle mentioned above, the transformation from $\mathbf{2 7}$ to $\mathbf{2 8}$ (and $\mathbf{3 1}$ to 32 ) is not unreasonable and is likely to occur under suitable reaction conditions. However, an alternative reaction pathway is worth considering, especially in the absence of strong oxidants (Figure 17).

One should consider that the oxidation of the carbon radical to the carbenium ion requires the open-shell species to come in proximity to the oxidized PC. However, the PC is only present in catalytic amounts and this bimolecular electron transfer may not necessarily be a fast process.

Alternatively, photocatalytic reactions often use base in stoichiometric (or even excess) quantities. Because the concentration of base is much greater than that of the $P C$, it is conceivable that, instead of the commonly proposed $\mathrm{e}^{-} / \mathrm{H}^{+}$loss, the order of operations may be to remove $\mathrm{H}^{+} / \mathrm{e}^{-}$.

Consider the deprotonation of $\mathbf{2 7}$ and the subsequent formation of radical anion 28'. Not only will 28' be easier to oxidize by the PC than 27 but situationally, 28' may be capable of injecting an electron into $R-Y$ (instead of the $\mathrm{PC})$, thus propagating the reaction.

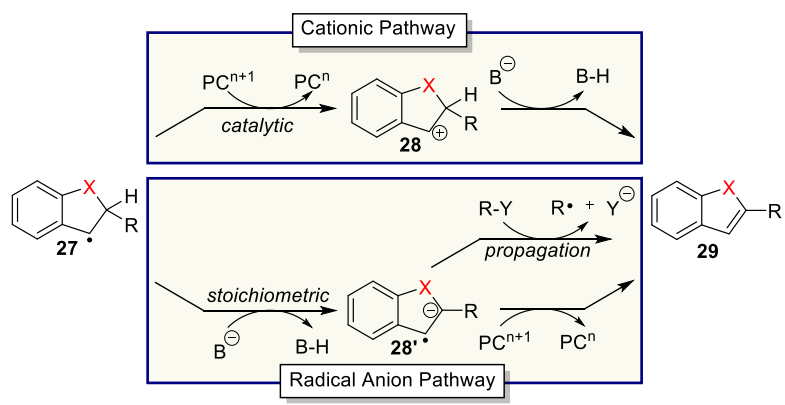

Figure 17. Schematic representation for the final steps in a radical addition to heteroarenes. Top: Cationic pathway, loss of $\mathrm{e}^{-}$then $\mathrm{H}^{+}$. Bottom: Radical anion pathway, loss of $\mathrm{H}^{+}$then $\mathrm{e}^{-}$.

We conclude by evaluating the possibility of electron upconversion via radical addition to heteroarenes (e.g., benzofuran and indoles) and in coumarin synthesis (Figure 18). In order to simulate the common reaction conditions, we explored a selection of frequently used solvents (DMF, DMSO, and MeCN) and three bases, i.e., trimethylamine (TMA), hydroxide, and carbonate that can assist in the formation of a radical anion via deprotonation of a radical.

In the presence of a strong oxidant and/or a weak base, carbenium ion formation is certainly feasible. The role of base is important. For example, with TMA as a base, the formation of radical anions 35,37 , and 39 was found to be thermodynamically unfavorable (Figure 18).

However, in the presence of a suitable base, deprotonation and formation of radical anion prior to oxidation becomes feasible. This preference is illustrated by the deprotonation of radicals 34, 36, and 38 (Figure 18) which becomes exergonic in the reactions with hydroxide and carbonate. Furthermore, as the acidity of the $\mathrm{C}-\mathrm{H}$ bond increases, the formation of radical anions becomes more favorable. This 
is clearly observed in the deprotonation of radical $\mathbf{4 0}$, in which all three bases were found to be suitable for radical anion formation 41 .

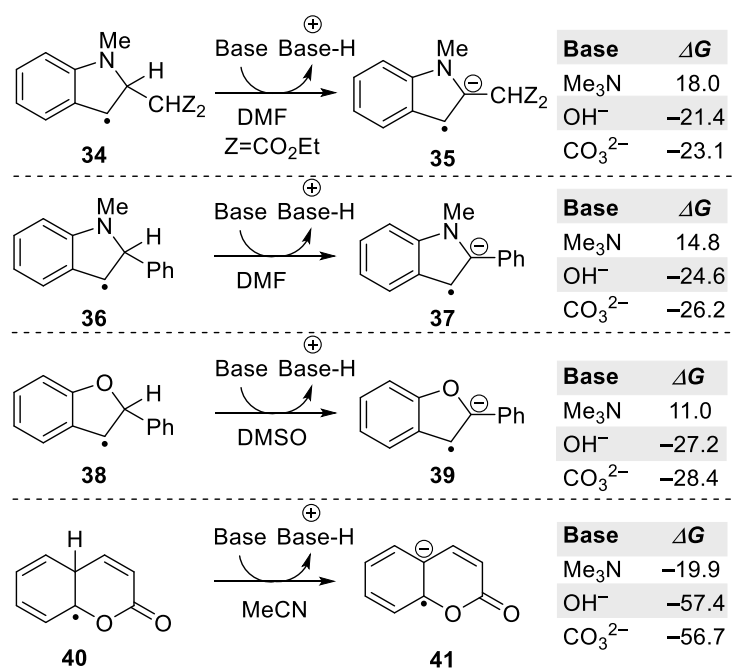

Figure 18. Reaction energies for radical anion formation. Four separate reactants 34, 36, 38 and 40 were looked at, along with three bases $\left(\mathrm{Me}_{3} \mathrm{~N}, \mathrm{OH}^{-}\right.$ and $\left.\mathrm{CO}_{3}{ }^{2-}\right)$. Three common solvents for photocyclization were explored: DMF, DMSO, $\mathrm{MeCN}$.

\section{Conclusions}

The alternative routes to $\mathrm{C}-\mathrm{H}$ amination that involve intramolecular (2c,3e)-C-N bond formation has been investigated with DFT calculations. Dialkyl 2-(3(arylamino)propyl)malonates similar to the one used in the electrochemical cyclization of $\mathrm{Xu}$ et al. are predicted to be capable of a thermodynamically feasible cyclization from a radical anionic species. ${ }^{51}$ Additionally, we found that a more electron deficient nitrogen center should favor the cyclization. In contrast, an over-stabilization of the reactive center on the $\delta$-carbon and sterically demanding groups are predicted to have a negative impact on the energetics of the cyclization.

In particular, an interesting stereoelectronic feature for the reaction of $N$-radicals and malonate anions is that only one of the ester groups is involved in the extra electron delocalization in the cyclized radical anion product. In contrast, the acyclic reactants have two esters that can stabilize the anionic center. Such unproductive excessive reactant stabilization can be removed when enolates derived from monoesters are used as the starting materials, leading to much more favorable thermodynamics for the respective three-electron cyclizations.
Seven transition states were located for the model substrates with activation barriers ranging from $11 \mathrm{kcal} \mathrm{mol}^{-1}$ to $22 \mathrm{kcal} \mathrm{mol}^{-1}$. While the upper extreme of this range is likely to be less relevant for practical work due to potential side reactions, the high exergonicity of the overall process when combined with a mild terminal oxidant such as dioxygen should provide attractive opportunities for the design of new reactions based on electron upconversion.

Theoretical examinations of additional $\mathrm{C}-\mathrm{N}$ and $\mathrm{C}-\mathrm{C}$ bond forming reactions indicate that the concept of electron upconversion is likely to be relevant to a wider range of reactions (e.g., organo- and photocatalytic reactions). This alternative mechanism might be favored in situations in which a weaker oxidants and stronger bases are utilized.

\section{Data availability}

A detailed version of Figure 6 can be found in the ESI. Furthermore, the results of a benchmark for the free energy of the radical anion cyclization against different levels of theories are included in the ESI. The DFT optimized geometries for all compounds and for unrestricted compounds the spin-squared expectation value $\left\langle S^{2}\right\rangle$ related to the calculation can be found in the ESI. An animation of the radical anion cyclization can be found as supplementary information.

\section{Author contributions}

T. O. and I. V. A. conceived and supervised the project. $¥ P$. E. and $Q$. E. contributed equally to this work. All authors contributed to manuscript edits.

\section{Conflicts of interest}

The authors declare no conflicts of interest.

\section{Acknowledgments}

Parts of this research were conducted using the supercomputer Mogon II and/or advisory services offered by Johannes Gutenberg University Mainz (hpc.uni-mainz.de), which is a member of the AHRP (Alliance for High Performance Computing in Rhineland Palatinate, www.ahrp.info) and the Gauss Alliance e.V. The authors gratefully acknowledge the computing time granted on the supercomputer Mogon at Johannes Gutenberg University Mainz (hpc.uni-mainz.de). 
Research at FSU is supported by the National Science Foundation (CHE-2102579)

\section{Notes and references}

1. C.-J. Li, Acc. Chem. Res., 2009, 42 , 335-344.

2. S. A. Girard, T. Knauber and C.-J. Li, Angew. Chem. Int. Ed., 2014, 53, 74100.

3. C. J. Scheuermann, Chem. Asian J., 2010, 5, 436-451.

4. W.-J. Yoo and C.-J. Li, in $C-H$ Activation, eds. J.-Q. Yu and Z. Shi, Springer Berlin Heidelberg, Berlin, Heidelberg, 2010, pp. 281-302.

5. A. A. Almasalma and E. Mejía, in Heterocycles via Cross Dehydrogenative Coupling: Synthesis and Functionalization, eds. A. Srivastava and C. K. Jana, Springer Singapore, Singapore, 2019, pp. 329356.

6. F. A. H. Nasab, L. Z. Fekri, A. Monfared, A. Hosseinian and E. Vessally, RSC Adv., 2018, 8, 1845618469.

7. A. Hosseinian, S. Farshbaf, L. Z. Fekri, M. Nikpassand and E. Vessally, Top. Curr. Chem., 2018, 376, 23.

8. I. B. Krylov, V. A. Vil and A. O. Terent'ev, Beilstein J. Org. Chem., 2015, 11, 92-146.

9. W. Peng, E. Vessally, S. Arshadi, A. Monfared, A. Hosseinian and L. Edjlali, Top. Curr. Chem., 2019, 377, 1-22.

10. A. Batra, P. Singh and K. N. Singh, Asian J. Org. Chem., 2021, 10, 10241049.

11. A. S. K. Tsang, S. J. Park and M. H. Todd, in From C-H to C-C Bonds: Cross-Dehydrogenative-Coupling, The Royal Society of Chemistry, 2015, pp. 254-294.

12. L. Dai, Z.-H. Xia, Y.-Y. Gao, Z.-H. Gao and S. Ye, Angew. Chem. Int. Ed., 2019, 58, 18124-18130.

13. Y. Wang, P. Qian, J.-H. Su, Y. Li, M. Bi, Z. Zha and Z. Wang, Green Chem., 2017, 19, 4769-4773.

14. N. T. Jui, J. A. O. Garber, F. G. Finelli and D. W. C. MacMillan, JACS, 2012, 134, 11400-11403.

15. N. T. Jui, E. C. Y. Lee and D. W. C. MacMillan, JACS, 2010, 132, 1001510017.

16. M. Gong and J.-M. Huang, Chem. Eur. J., 2016, 22, 14293-14296.

17. C. J. Evoniuk, S. P. Hill, K. Hanson and I. V. Alabugin, Chem. Commun., 2016, 52, 7138-7141.
18. Z.-Y. Song, K.-Q. Chen, X.-Y. Chen and S. Ye, J. Org. Chem., 2018, 83, 2966-2970.

19. Q. Chen, T. Zhu, P. K. Majhi, C. Mou, H. Chai, J. Zhang, S. Zhuo and Y. R. Chi, Chem. Sci., 2018, 9, 8711-8715.

20. W.-Y. Chen, K.-Q. Chen, D.-Q. Sun and S. Ye, Chem. Sci., 2017, 8, 1936-1941.

21. L. Pauling, JACS, 1931, 53, 1367-1400.

22. Z.-W. Hou, Z.-Y. Mao, Y. Y. Melcamu, X. Lu and H.-C. Xu, Angew. Chem. Int. Ed., 2017, 57, 1636-1639.

23. T. O. Paulisch, F. Strieth-Kalthoff, C. Henkel, L. Pitzer, D. M. Guldi and F. Glorius, Chem. Sci., 2020, 11, 731-736.

24. M. A. Syroeshkin, F. Kuriakose, E. A. Saverina, V. A. Timofeeva, M. P. Egorov and I. V. Alabugin, Angew. Chem. Int. Ed., 2018, 58, 5532-5550.

25. A. Studer and D. P. Curran, Nat. Chem., 2014, 6, 765-773.

26. E. M. Alvarez, T. Karl, F. Berger, L. Torkowski and T. Ritter, Angew. Chem. Int. Ed., 2021, 60, 13609-13613.

$27 . \quad J$. Zhang, J.-D. Yang and J.-P. Cheng, Chem. Sci., 2020, 11, 8476-8481.

28. M. Lübbesmeyer, E. G. Mackay, M. A. R. Raycroft, J. Elfert, D. A. Pratt and A. Studer, JACS, 2020, 142, 2609-2616.

29. S. Rohrbach, R. S. Shah, T. Tuttle and J. A. Murphy, Angew. Chem. Int. Ed., 2019, 58, 11454-11458.

30. Q. Elliott, G. dos Passos Gomes, C. J. Evoniuk and I. V. Alabugin, Chem. Sci., 2020, 11, 6539-6555.

31. C. J. Evoniuk, G. d. P. Gomes, S. P. Hill, S. Fujita, K. Hanson and I. V. Alabugin, JACS, 2017, 139, 1621016221.

32. J. V. Burykina, N. S. Shlapakov, E. G. Gordeev, B. König and V. P. Ananikov, Chem. Sci., 2020, 11, 10061-10070.

33. A. J. Greener, P. Ubysz, W. OwensWard, G. Smith, I. Ocaña, A. C. Whitwood, V. Chechik and M. J. James, Chem. Sci., 2021, 43, 14641-14646.

34. J. P. Barham, S. E. Dalton, M. Allison, G. Nocera, A. Young, M. P. John, T. McGuire, S. Campos, T. Tuttle and J. A. Murphy, JACS, 2018, 140, 1151011518.

35. G. Nocera, A. Young, F. Palumbo, K. J. Emery, G. Coulthard, T. McGuire, T. Tuttle and J. A. Murphy, JACS, 2018, 140, 9751-9757.

36. J. P. Barham, G. Coulthard, K. J. Emery, E. Doni, F. Cumine, G. Nocera, M. P. John, L. E. A. Berlouis, T. McGuire, T. Tuttle and J. A. Murphy, JACS, 2016, 138, 7402-7410.

37. J.P. Barham, G. Coulthard, R. G. Kane, N. Delgado, M. P. John and J. A. 
Murphy, Angew. Chem. Int. Ed., 2016, 55, 4492-4496.

38. Sushmita, T. Aggarwal, K. M. Saini and A. K. Verma, Adv. Synth. Catal., 2021, 363, 4555-4560.

39. Y.-C. He, Y.-M. Yan, Z.-X. Ren, Y.-Z. Wang, Q. Yu, J. Xiong and M.-L. Wang, Adv. Synth. Catal., 2021, 363, 10381043.

40. I. A. Dmitriev, V. V. Levin and A. D. Dilman, Org. Lett., 2021, 23, 89738977.

41. M. Kischkewitz, F. W. Friese and A. Studer, Adv. Synth. Catal., 2020, 362, 2077-2087.

42. M. J. Frisch, G. W. Trucks, H. B. Schlegel, G. E. Scuseria, M. A. Robb, J. R. Cheeseman, G. Scalmani, V. Barone, G. A. Petersson, H. Nakatsuji, X. Li, M. Caricato, A. V. Marenich, J. Bloino, B. G. Janesko, R. Gomperts, B. Mennucci, H. P. Hratchian, J. V. Ortiz, A. F. Izmaylov, J. L. Sonnenberg, Williams, F. Ding, F. Lipparini, F. Egidi, J. Goings, B. Peng, A. Petrone, T. Henderson, D. Ranasinghe, V. G. Zakrzewski, J. Gao, N. Rega, G. Zheng, W. Liang, M. Hada, M. Ehara, K. Toyota, R. Fukuda, J. Hasegawa, M. Ishida, T. Nakajima, Y. Honda, O. Kitao, H. Nakai, T. Vreven, K. Throssell, J. A. Montgomery Jr., J. E. Peralta, F. Ogliaro, M. J. Bearpark, J. J. Heyd, E. N. Brothers, K. N. Kudin, V. N. Staroverov, T. A. Keith, R. Kobayashi, J. Normand, K. Raghavachari, A. P. Rendell, J. C. Burant, S. S. lyengar, J. Tomasi, M. Cossi, J. M. Millam, M. Klene, C. Adamo, R. Cammi, J. W. Ochterski, R. L. Martin, K. Morokuma, O. Farkas, J. B. Foresman and D. J. Fox, GAUSSIAN 16 (Revision A.03), Gaussian Inc., Wallingford, CT, 2016.

43. Y. Zhao and D. G. Truhlar, Theor. Chem. Acc., 2008, 120, 215-241.

44. Y. Zhao and D. G. Truhlar, Acc. Chem. Res., 2008, 41, 157-167.

45. T. Clark, J. Chandrasekhar, G. W. Spitznagel and P. V. R. Schleyer, J. Comput. Chem., 1983, 4, 294-301.

46. W. J. Hehre, R. Ditchfield and J. A. Pople, J. Chem. Phys., 1972, 56, 22572261.

47. S. Grimme, J. Antony, S. Ehrlich and H. Krieg, J. Chem. Phys., 2010, 132, 154104.

48. A. V. Marenich, C. J. Cramer and D. G. Truhlar, J. Phys. Chem. B, 2009, 113, 6378-6396.

49. V. Alonso, J. A. González, I. García de la Fuente and J. C. Cobos,
Thermochim. Acta, 2012, 543, 246253.

50. A. Estabragh, M. Kholoosi, F. Ghaziani and A. Javadi, J. Environ. Eng. (New York), 2017, 143, 04017054.

51. Z. J. Wu, S. R. Li and H. C. Xu, Angew. Chem. Int. Ed., 2018, 57, 14070-14074.

52. C. Riplinger, P. Pinski, U. Becker, E. F. Valeev and F. Neese, J. Chem. Phys., 2016, 144, 024109.

53. F. Neese, Wiley Interdiscip. Rev. Comput. Mol. Sci., 2012, 2, 73-78.

54. F. Neese, Wiley Interdiscip. Rev. Comput. Mol. Sci., 2018, 8, e1327.

55. E. F. Valeev, Libint: A library for the evaluation of molecular integrals of many-body operators over Gaussian functions, Version 2.7.0-beta.6, http://libint.valeyev.net/).

56. J. T. H. Dunning, J. Chem. Phys., 1989, 90, 1007-1023.

57. F. Weigend, A. Köhn and C. Hättig, J. Chem. Phys., 2002, 116, 3175-3183.

58. Chemcraft - graphical software for visualization of quantum chemistry computations.,

https://www.chemcraftprog.com).

59. S. Zhang, L. Li, M. Xue, R. Zhang, K. Xu and C. Zeng, Org. Lett., 2018, 20, 3443-3446.

60. Z.-W. Hou, D.-J. Liu, P. Xiong, X.-L. Lai, J. Song and H.-C. Xu, Angew. Chem. Int. Ed., 2021, 60, 2943-2947.

61. Z. Wan, D. Wang, Z. Yang, H. Zhang, S. Wang and A. Lei, Green Chem., 2020, 22, 3742-3747.

62. P. Wang, Z. Yang, T. Wu, C. Xu, Z. Wang and A. Lei, ChemSusChem, 2019, 12, 3073-3077.

63. Y.-Z. Zheng, B. Chen, P. Ye, K. Feng, W. Wang, Q.-Y. Meng, L.-Z. Wu and C.$\mathrm{H}$. Tung, JACS, 2016, 138, 1008010083.

64. H. Yi, L. Niu, C. Song, Y. Li, B. Dou, A. K. Singh and A. Lei, Angew. Chem. Int. Ed., 2017, 56, 1120-1124.

65. L. Niu, H. Yi, S. Wang, T. Liu, J. Liu and A. Lei, Nat. Commun., 2017, 8, 14226.

66. M. A. Kaila, A. Levens and D. A. Nicewicz, Angew. Chem. Int. Ed., 2017, 56, 15644-15648.

67. L. W. Hernandez, W. P. Gallagher, C. A. Guerrero, F. Gonzalez-Bobes and J. R. Coombs, J. Org. Chem., 2021, 86, 10903-10913.

68. H.-L. Wang, M. Shang, S.-Z. Sun, Z.-L. Zhou, B. N. Laforteza, H.-X. Dai and J.Q. Yu, Org. Lett., 2015, 17, 1228-1231.

69. W. N. Olmstead, Z. Margolin and F. G. Bordwell, J. Org. Chem., 1980, 45, 3295-3299. 
70. J. M. Goodman, P. D. Kirby and L. O. Haustedt, Tetrahedron Lett., 2000, 41, 9879-9882.

71. W. Wynne-Jones and H. Eyring, J. Chem. Phys., 1935, 3, 492-502.

72. P. Stilbs and S. Forsen, J. Phys. Chem., 1971, 75, 1901-1902.

73. M. J. Bausch, C. Guadalupe-Fasano, R. Gostowski, D. Selmarten and A. Vaughn, J. Org. Chem., 1991, 56, 5640-5642.

74. F. G. Bordwell and D. J. Algrim, JACS, 1988, 110, 2964-2968.

75. A. Kumar and M. D. Sevilla, J. Phys. Chem., 2018, 122, 98-105.

76. Y. Wang, H. Zhang, M. Pink, A. Olankitwanit, S. Rajca and A. Rajca, JACS, 2016, 138, 7298-7304.

77. L. Abella, J. Crassous, L. Favereau and J. Autschbach, Chem. Mater., 2021.

78. G. Gryn'ova and M. L. Coote, JACS, 2013, 135, 15392-15403.

79. G. Gryn'ova, D. L. Marshall, S. J. Blanksby and M. L. Coote, Nat. Chem., 2013, 5, 474-481.

80. X. M. Zhang, F. G. Bordwell, M. Van Der Puy and H. E. Fried, J. Org. Chem., 1993, 58, 3060-3066.

81. E. M. Arnett, S. G. Maroldo, S. L. Schilling and J. A. Harrelson, JACS, 1984, 106, 6759-6767.

82. W. N. Olmstead, Z. Margolin and F. G. Bordwell, J. Org. Chem., 1980, 45, 3295-3299.

83. C. Hansch, A. Leo and R. Taft, Chem. Rev., 1991, 91, 165-195.

84. J. H. Blanch, J. Chem. Soc. B, 1966, 937-939.

85. I. Gallardo and N. Vilà, J. Org. Chem., 2010, 75, 680-689.

86. I. Gallardo and N. Vilà, J. Org. Chem., 2008, 73, 6647-6656.

87. We were unable to find $p K_{a}$ values for the conjugate acid of $\mathrm{Na}_{2} \mathrm{HPO}_{4}$ and $p$ -
$\mathrm{NO}_{2}-\mathrm{C}_{6} \mathrm{H}_{4}-\mathrm{SO}_{2}-\mathrm{NH}_{2}$ in DME. However, in water the conjugate acid of $\mathrm{Na}_{2} \mathrm{HPO}_{4}$ has a $p K_{a}$ of 7.2. The $p K_{a}$ of $p-\mathrm{NO}_{2}-$ $\mathrm{C}_{6} \mathrm{H}_{4}-\mathrm{SO}_{2}-\mathrm{NH}_{2}$ in water has been reported to be 10 . Given the fact that compound 23 has a formal positive charge, the $\mathrm{p} K_{\mathrm{a}}$ of the $\mathrm{N}-\mathrm{H}$ bond should be $<10$. Under the reaction conditions outlined in this work, it is possible that a nitrogen anion exists and is capable of trapping a carbon radical.

88. E. Kimura, Pure Appl. Chem., 1993, 65, 355-359.

89. D. P. Hari, P. Schroll and B. König, JACS, 2012, 134, 2958-2961.

90. L. Furst, M. S. Bryan, J. M. R. Narayanam, J. W. Tucker and C. R. J. Stephenson, Org. Lett., 2010, 12, 31043107.

91. J. W. Tucker, J. M. R. Narayanam, S. W. Krabbe and R. J. Stephenson, Org. Lett., 2010, 12, 368-371.

92. A. Wetzel, G. Pratsch, R. Kolb and M. R. Heinrich, Chem. Eur. J., 2010, 16, 2547-2556.

93. Y.-F. Zeng, D.-H. Tan, Y. Chen, W.-i. Lv, X.-G. Liu, Q. Li and H. Wang, Org. Chem. Front., 2015, 2, 1511-1515.

94. X. Mi, C. Wang, M. Huang, J. Zhang, Y. $\mathrm{Wu}$ and $\mathrm{Y}$. Wu, Org. Lett., 2014, 16, 3356-3359.

95. W. Fu, M. Zhu, G. Zou, C. Xu, Z. Wang and B. Ji, J. Org. Chem., 2015, 80, 4766-4770.

96. W. Yang, S. Yang, P. Li and L. Wang, Chem. Commun., 2015, 51, 75207523.

97. Y. Li, Y. Lu, G. Qiu and Q. Ding, Org. Lett., 2014, 16, 4240-4243.

98. Q. Zhou, F.-T. Xiong, P. Chen, B.-Q. Xiong, K.-W. Tang and Y. Liu, Org. Biomol. Chem., 2021, 19, 9012-9020. 